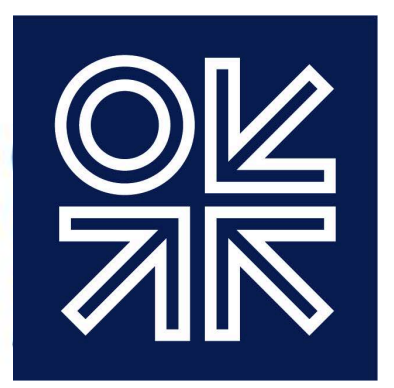

THE OXFORD

INSTITUTE

FOR ENERGY

STUDIES

July 2019

\title{
Determinants of WTP among energy-poor households:
} implications for planning models and frameworks 

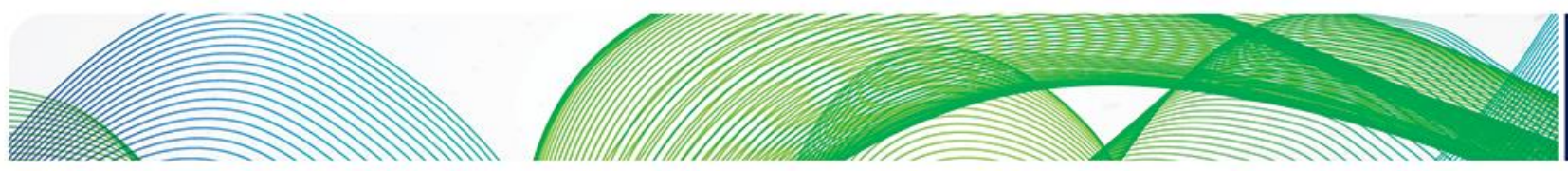

\section{잊조}

The contents of this paper are the author's sole responsibility. They do not necessarily represent the views of the Oxford Institute for Energy Studies or any of its members.

\section{Copyright @ 2019}

\section{Oxford Institute for Energy Studies}

(Registered Charity, No. 286084)

This publication may be reproduced in part for educational or non-profit purposes without special permission from the copyright holder, provided acknowledgment of the source is made. No use of this publication may be made for resale or for any other commercial purpose whatsoever without prior permission in writing from the Oxford Institute for Energy Studies.

ISBN 978-1-78467-142-6

DOI: https://doi.org/10.26889/9781784671426 


\title{
Determinants of WTP among energy-poor households: Implications for planning models and frameworks
}

\author{
Roxanne Rahnama \\ OIES - Saudi Aramco Fellow, Oxford Institute for Energy Studies, Oxford, UK
}

\begin{abstract}
:
Electrification rates in low-income countries have faced steady improvements in the last few decades, with impressive technological advances having been made in both grid and off-grid electricity supply channels. Nonetheless, the persistent demand- and supply-side challenges of electricity access and reliability, predominantly in Asia and sub-Saharan Africa, reduce the feasibility of universal electricity access by 2030. In particular, while governments and firms have made measurable progress in investing in the expansion of supply along the extensive margin (increases in access), there has been less improvement in the rate of electrification along the intensive margin (increasing quality of supply and reliability). These gaps have given rise to a growing research agenda on both the demand and the willingness to pay (WTP) for the expansion of electrification, with diverse technologies along both margins in urban and rural settings. Motivated by this agenda, I use survey data from six states in India to conduct a descriptive analysis of socioeconomic, behavioural, and technical factors that correlate with variations in household valuation of electricity access and reliability in rural municipalities. The aim is not to provide causal evidence but, rather, insights into which potential factors explain energy-poor households' decision making and WTP for a spectrum of electricity services from both grid and off-grid supply technologies. Recommendations are provided on the ways in which these insights can both further expand how energy poverty and WTP are measured within general access frameworks, as well as in optimization tools for national electrification planning through the use of proxy metrics, including the cost of non-served energy.
\end{abstract}



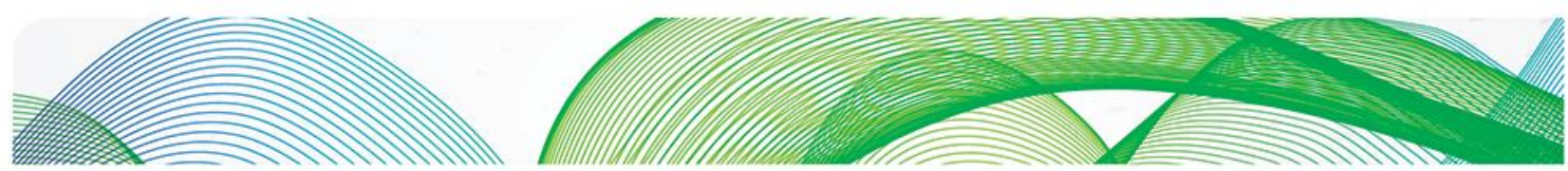

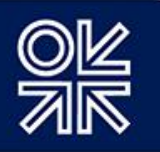

\section{Contents}

Abstract:

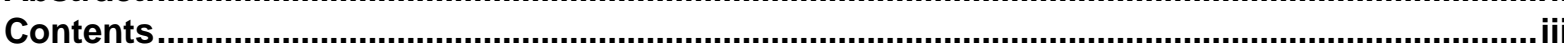

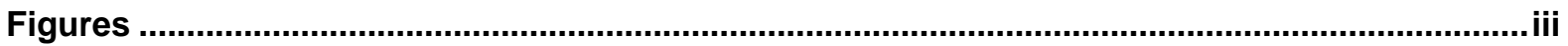

Tables

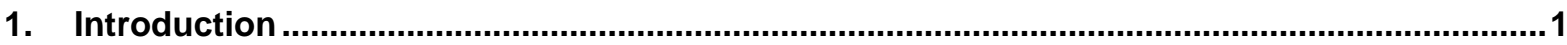

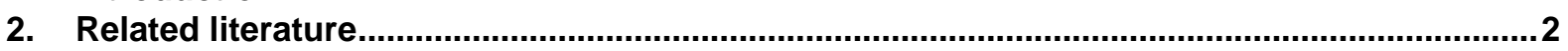

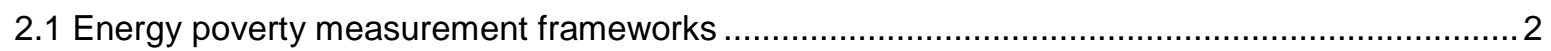

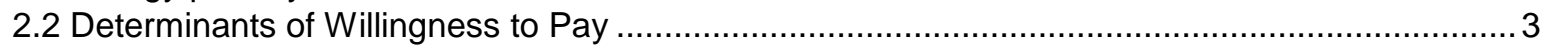

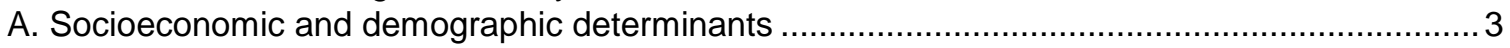

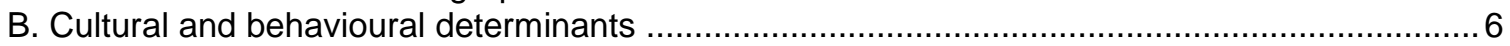

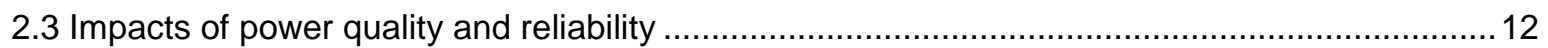

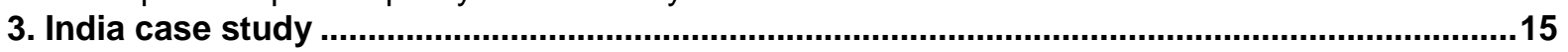

3.1 ACCESS: access to clean cooking, energy, and electricity - survey of states in India ..............16

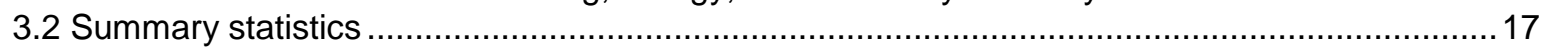

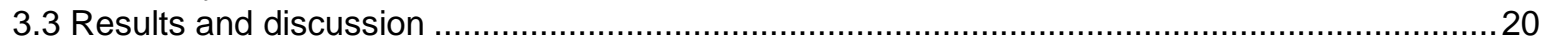

4. WTP in technoeconomic planning and optimization models ..............................................22

4.1 Enhancing existing proxy measures in technoeconomic models ..........................................23

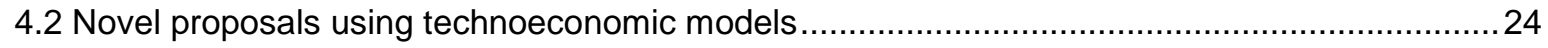

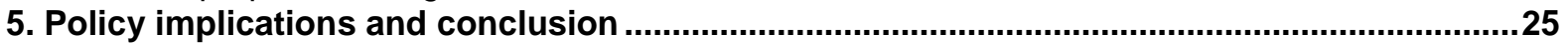

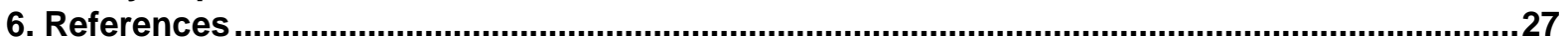

\section{Figures}

Figure 1: Average WTP, based on provider expected to be responsible for electricity ......................... 7

Figure 2: Electricity theft, attitudes toward tariff hikes, and bill payment strategy design ....................10

Figure 3: Appliance ownership and aspiration, by connection type ................................................ 19

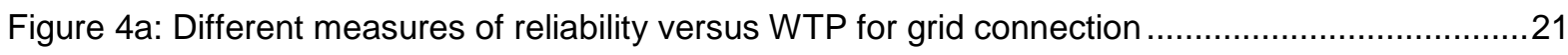

Figure 4b: Different measures of reliability versus WTP for standard package .................................21

\section{Tables}

Table 1: Socioeconomic and Demographic Correlates of Willingness to Pay ......................................

Table 2: Behaviour and Energy Projects in AEA RCT Registry (2014-2018) ...................................... 8

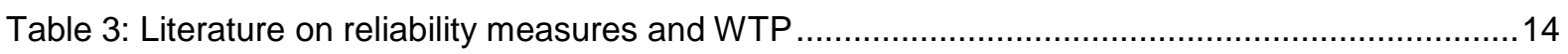

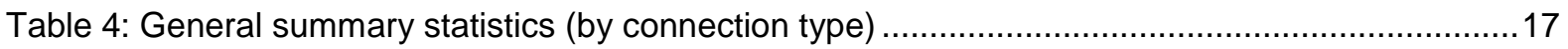

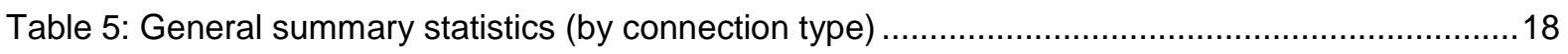

Table 6: Average WTP, by attitudes toward theft and awareness of solar .......................................20

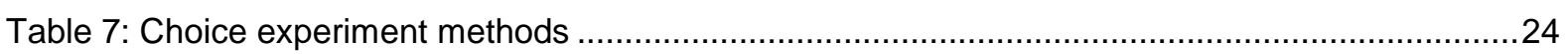



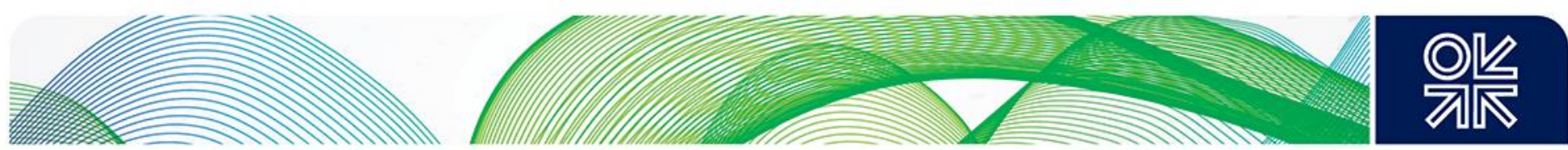

\section{Introduction}

The reliable delivery of an electricity supply across a spectrum of urban and rural households in lowincome countries mandates a multidimensional understanding of consumers within the diverse sociocultural contexts in which they are embedded. However, traditional models for measuring energy poverty are largely static in their temporality, confined to binary indicators, and assume linearity between income and fuel choice (Elnakat et al., 2016; Sovacool, 2014; Aune 2007). In particular, electricity consumers have been subdivided into binary categorizations based on the form of electricity access (such as grid or off-grid). While off-grid systems are well understood to constitute microgrids, minigrids, and standalone solar systems, the gradient of the consumer base that exists between the grid and off the grid is more nuanced. For example, Lee et al. (2016b) coined the term 'under grid' in a study on rural electrification in Kenya, using it to describe households that are close enough to connect to a lowvoltage line but are not connected for a variety of reasons, such as high connection costs. Moreover, in a report from 2017, M-KOPA (a large-scale off-grid solar company based in sub-Saharan Africa) furthered this segmentation of consumers with categories such as 'idle grid', which represents households that are connected to the grid through rural electrification programmes, but which generally cannot afford appliances. These subtler segmentations of electricity consumers in non-OECD settings matter because each faces a different degree of challenge that holds implications for consumers' demand and WTP for the level of service within that category. In certain cases, some consumers fall under multiple categories simultaneously - using off-grid connections or turning to kerosene to cope with under grid, idle grid, or bad grid connections. This fragmentation can influence how consumers value electricity along extensive and intensive margins, which has further implications for the ways in which companies customize their product offerings and also how policymakers measure their own progress in reaching true universal electrification targets.

Despite growing progress in the development of multitier metrics that aim to measure and track these fragmentations of consumers - disaggregating energy services, productive uses, and needs at household and community levels - the availability, reliability, and affordability dimensions of electricity services nonetheless continue to be difficult to capture (Pelz et al., 2018). In particular, large gaps persist in the literature on socioeconomic, political, psychological, and cultural determinants of household and individual-level variation in energy use, behavioural response to poor reliability, WTP, and aspirations (Tait, 2017; Broto et al., 2017; Aklin et al., 2015). In simultaneity with the onset of multitier frameworks, there have also been advances in geospatial modelling and electrification planning tools that can be used by governments and the private sector in streamlining the analysis of electricity supply options. While decision support tools facilitate trade-off analysis between cost and technical performance outcomes, they are nonetheless constrained by similar gaps in measurement of household energy preferences, determinants of behaviour, and WTP (Rahnama and Perez-Arriaga, 2018; Gibson, 2017). A natural question, then, is: how can such optimization tools and access frameworks adapt to better incorporate behavioural and political economy considerations into the proxies that are used to measure and address energy poverty and access, along both extensive and intensive margins in low-income countries?

I frame the paper around this core question. In particular, I first focus on the potential socioeconomic, behavioural, and technical factors (such as low reliability) that determine household WTP for electricity services across different low-income non-OECD countries, with a particular focus on sub-Saharan Africa and India. As the core unique contribution of this paper to the existing literature, I next consider implications for the proxy measures of willingness to pay used in planning models, and hypothesize diverse scenario outcomes based upon the current state of knowledge on the determinants of willingness to pay. This paper contributes to three main bodies of literatures, including: 

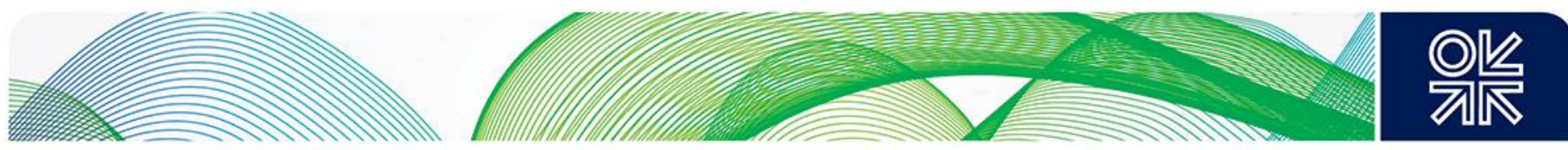

- the growing literature on energy poverty measurement frameworks (Pelz et al., 2018; Broto et al., 2017; Bouzarovski and Petrova, 2015);

- the nascent literature on the socioeconomic, cultural, and behavioural determinants of WTP and support for price reform (Blankenship et al., 2019);

- the recent research agenda on the economic consequences of differing patterns of reliability and power quality in developing countries (Lee et al., 2017).

This growing research agenda, which aims to advance understanding of consumers, their behaviours, and preferences, is essential not only for its impacts on measuring electrification, but also for its potential implications on building widespread acceptance of large-scale 'green' energy efficiency programmes in Low Income and Developing Countries (LIDCs), such as shifting to CFL lighting and smart metering. ${ }^{1}$

The remainder of the paper is structured as follows: Section 2 includes an overview of related literature; Section 3 describes the data used and results of a case study analysis in India; Section 4 considers implications for proxy measure design in optimization tools, laying out a series of thought experiments and proposals; and Section 5 considers policy implications and concludes.

\section{Related literature}

\subsection{Energy poverty measurement frameworks}

This paper contributes to the growing literature on modern multidimensional approaches for measuring energy poverty and access. While there is no universally agreed upon metric for energy poverty, the discourse around measurement in the last decade does converge in its emphasis on framing energy poverty in terms of a lack of affordable and reliable energy services - such as lighting, cooking, heating, mobility, communication, and entertainment - for both consumption and productive uses by households and businesses (Culver, 2017). Although energy services are not easily measured in terms of fungible units, and different forms of services are not substitutable, the underlying assumption that energy services go beyond a simple electricity connection has nonetheless given rise to a set of multitier and composite measures. These measures each vary in their strengths and weaknesses: for example, the World Bank Multitier Framework (MTF) is considered to be 'the most sophisticated energy poverty metric based on the quality of energy delivered', encompassing seven core attributes of quality ${ }^{2}$ that collectively incorporate a spectrum of the qualitative and quantitative characteristics of different technologies (Culver, 2017). At the same time, however, the aggregated MTF index has been critiqued for the ways in which it has equally weighted household, ${ }^{3}$ productive, and community energy without substantial supportive evidence (Groh et al., 2016). Each of the other three main composite metrics,

\footnotetext{
While green energy in LIDCs is not a focus of this paper, one paper that nicely demonstrates this link between the important research agenda on consumer WTP and behavioural response and energy efficiency programmes is summarized in Sudarshan (2017). This 'nudge' experiment, which was conducted in New Delhi, had two treatment groups: the first group received weekly report cards providing feedback on households' electricity consumption from the grid (low cost) and from backup diesel power (high cost), as well as comparisons with the consumption of others in the community and general savings tips. In contrast, the second treatment group received the same weekly reports, but was also enrolled in a monetary rewards scheme, where starting balances would increase if consumption was lower than that of peers and, conversely, decrease if it was higher. The study had three major findings: (1) the weekly report card group (without the rewards scheme) reduced average electricity usage by 7 per cent, except during outages; (2) the information nudges also made households more responsive to tariffs; and (3) interestingly, when monetary incentives were added, households no longer reduced consumption, possibility because of 'emerging distrust when offered a financial contract', particularly in an already low-trust environment.

2 The seven main dimensions for measuring electricity supply in the MTF include peak capacity, availability, reliability, legality, health and safety, affordability, and quality (Bhatia and Angelou, 2015).

${ }^{3}$ Tait (2017), for example, has found (in a study in South Africa) a situation in which households with similar median incomes, yet different sizes, have drastically diverse consumption patterns and deprivations along different dimensions; this illustrates some of the difficulties embedded in using household-level consumption measurements as a proxy for energy poverty.
} 

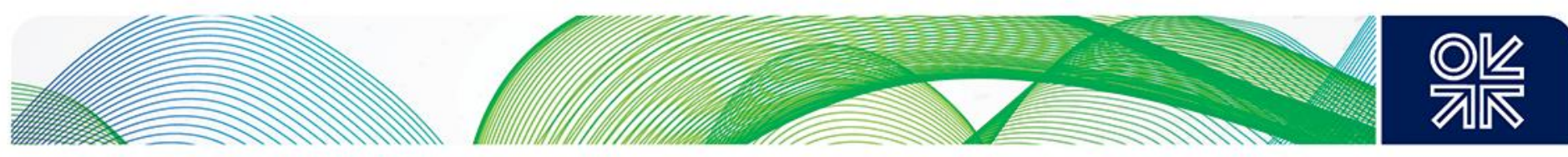

namely the Energy Development Index (EDI), Multidimensional Energy Poverty Index (MEPI), and Energy Poverty Index (EDI), have been similarly critiqued for the implications that arise from the ways in which the components of the indices are weighted and aggregated (Nussbaumer et al., 2012; Mirza and Szirmai, 2010).

In spite of the immense progress that has been made in advancing measurement frameworks beyond singular statistics - such as the number of household connections to a grid - the existing frameworks continue to lack cohesive and comprehensive measures that capture who the energy poor are, the factors that influence their preferences and WTP along a spectrum of technology options, and what the poor themselves consider as representing a satisfaction of their basic energy needs. In particular, existing measures struggle to account for the ways in which consumer preferences and culture significantly affect 'energy service needs, appliances used to satisfy these needs, and consequently, energy demand and cost of delivery' (Nussbaumer et al., 2012). Even though normative definitions of basic needs are subjective - varying on the basis of geography, culture, and differences in the social and politically accepted levels of supply disruption (Bhatia and Angelou, 2015; Tait, 2017) - there is nonetheless much room for further research and gathering of data that quantifies determinants of WTP in country-specific contexts. Given the powerful ways in which these metrics inform decision making such as by helping policymakers to identify trade-offs between different supply technologies in both the short and long run, to set reliability and access targets, and to develop collaborations between households, utilities, financial institutions, and community groups - additional steps are necessary to improve quantification of the dynamics of energy poverty and household behaviour (Pelz, 2018). This paper aims to further this research agenda through a comprehensive analysis of the existing state of knowledge on factors that influence WTP among the energy poor. In doing so, I highlight areas for further research and hypotheses regarding the ways in which the determinants of household decision making and WTP can impact current energy poverty measurement frameworks.

\subsection{Determinants of Willingness to Pay}

This paper also contributes to the small, yet growing, literature on determinants of willingness to pay (WTP). I examine this literature from two core angles: first, the socioeconomic and demographic factors that correlate with variability in WTP, and second, the behavioural and cultural determinants of electricity valuation and support for price reform. While there is a well-established body of literature on the former, existing literature on the latter is nascent and growing. Nuanced insights on these different determinants of WTP will allow for a more realistic integration of the attitudes and behaviour of consumers into new policy and business model proposals, as later discussed in Section 4.

Prior to diving into this literature, a brief note on important limitations of WTP measurement for the sake of transparency: there are a number of contingent valuation methods (CVM) that are often used in WTP studies (this method is detailed in Table 7) and these are often used to encourage respondents to consider trade-offs in the decisions they make. These different methods, however, have sometimes been criticized for failing to account for biases and strategic behaviours that may exist among respondents. For example, a respondent may change their reported WTP, relative to their true WTP, in order to influence the provision and cost of a good. Similarly, respondents may give 'protest zero' responses, in order to signal disagreement with the scenarios provided in the CVM survey (Hadker et al., 1997). Given the positives and negatives that exist for each of these WTP measurement methods, I try to provide a balanced sample of the methods used in WTP studies in the literature review in Sections 2.2-A, 2.2-B, and 2.3 ahead.

\section{A. Socioeconomic and demographic determinants}

Socioeconomic and demographic factors that either determine, or strongly correlate with, variation in WTP are better understood in the literature. In particular, variables such as educational status, income, caste, occupation, number of school children in the household, age, household structure, and whether the household runs a business indicate both interesting positive and negative effects on consumer WTP. Overall, there is consensus in the literature that higher educational status or years of education 

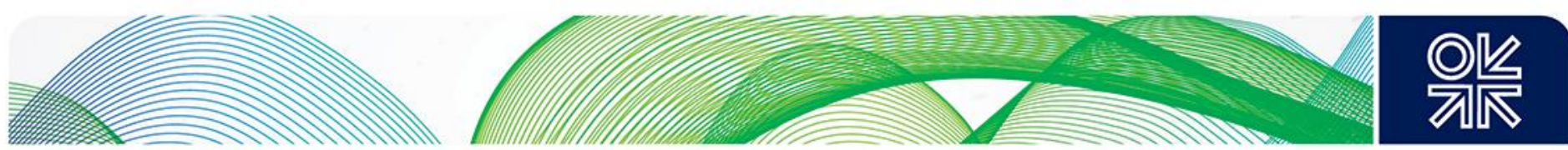

is associated with greater WTP for electricity (Gunatilake, 2012), as well as an increase in openness toward subsidy and other price reforms toward more cost-reflective tariffs (Garg et al., 2016; Aklin et al., 2014). Similarly, in a study conducted in the state of Madhya Pradesh in India, Gunatilake (2012) found that each additional child of school-going age in a household increases WTP by 4.3 per cent and if households rank electricity as their top government development priority (as compared to services such as water or education) they often have a higher WTP. Higher income levels and the existence of a home business also imply a higher WTP for reliable electricity services. For example, in an experiment conducted in Kenya, Abdullah and Jeanty (2009) find that individuals with entrepreneurial aspirations have higher WTP for reliable electricity. Similarly, in India, Gunatilake (2012) also finds that households with home businesses have a significantly higher propensity to value electricity more, as it can help to improve the business and their productivity.

Other parameters that have been examined in the literature indicate more ambiguity in the direction of effect. For example:

- Caste has an indeterminate effect on WTP: on the one hand, households may lack access due to social norms or discriminatory practices and may be willing to pay more more to overcome these constraints, on the other, some may be willing to pay less because of poverty or ingrained mental expectations of subsidies or free provision of power (Gunatilake, 2012; Blankenship et al., 2019).

- Age can also vary in its effect depending on context: while Taale and Kyeremeh (2016) find in Ghana that age has no measurable effect on WTP, Oseni et al. (2017) find in Nigeria that age is negatively correlated with the probability of a household engaging in self generation.

- Taale and Kyeremeh (2016) discuss the issue that households that use separate meters have a higher WTP for improvements in electricity supply than those that share meters.

Some of these findings may potentially be underscored by behavioural differences discussed in the following subsection. Table 1 summarizes key results below. 

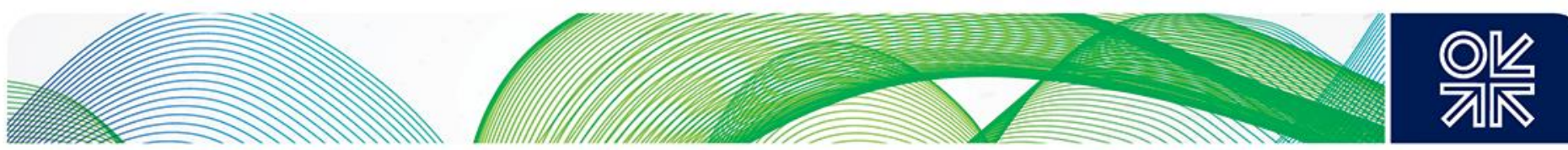

Table 1: Socioeconomic and Demographic Correlates of Willingness to Pay

\begin{tabular}{|c|c|c|c|c|c|}
\hline Parameter & Country & Description & $\begin{array}{l}\text { WTP Study } \\
\text { Methods }\end{array}$ & $\begin{array}{l}\text { Direction } \\
\text { of Effect }\end{array}$ & Source \\
\hline Education & India & $\begin{array}{l}\text { Effects of years of education or } \\
\text { highest educational status on WTP } \\
\text { and openness to price reform }\end{array}$ & $\begin{array}{l}\text { Bidding game }{ }^{4} \\
\text { Household survey }\end{array}$ & Positive & $\begin{array}{l}\text { Gunatilake (2012) } \\
\text { Garg et al. (2016) } \\
\text { Aklin et al. (2014) }\end{array}$ \\
\hline Caste & India & $\begin{array}{l}\text { Effects of caste status on household } \\
\qquad \text { WTP } \\
\text { (Schedule Castes, Schedule Tribes, } \\
\text { or Other Backward Class) }\end{array}$ & Bidding game & Ambiguous & Gunatilake (2012) \\
\hline Occupation & $\begin{array}{l}\text { India, } \\
\text { Kenya }\end{array}$ & $\begin{array}{l}\text { Effects of occupation (business, } \\
\text { agriculture, informal) on household } \\
\text { WTP }\end{array}$ & Bidding game & Ambiguous & $\begin{array}{l}\text { Gunatilake (2012) } \\
\text { M-Kopa (2017) }\end{array}$ \\
\hline Substitutions & India & $\begin{array}{l}\text { Effect of how highly households rank } \\
\text { electricity as a government } \\
\text { development priority on household } \\
\text { WTP }\end{array}$ & Bidding game & Positive & Gunatilake (2012) \\
\hline School Children & India & $\begin{array}{l}\text { Effect of how many school-going } \\
\text { children are in a household on WTP } \\
\text { for electricity services }\end{array}$ & Bidding game & Positive & Gunatilake (2012) \\
\hline Age & $\begin{array}{l}\text { Nigeria } \\
\text { Ghana }\end{array}$ & $\begin{array}{c}\text { Effects of age on household WTP } \\
\text { and loss of utility from electricity } \\
\text { outages }\end{array}$ & $\begin{array}{l}\text { Revealed preference } \\
\text { Household survey - } \\
\text { stated preference } \\
\text { CVM }\end{array}$ & Ambiguous & $\begin{array}{l}\text { Oseni et al. (2017) } \\
\text { Taale and } \\
\text { Kyeremeh (2016) }\end{array}$ \\
\hline $\begin{array}{l}\text { Household } \\
\text { Structure }\end{array}$ & Ghana & $\begin{array}{l}\text { Effects of living in detached houses } \\
\text { or with separate meters on WTP for } \\
\text { improvements in electricity services }\end{array}$ & $\begin{array}{l}\text { Household survey - } \\
\text { stated preference } \\
\text { CVM }\end{array}$ & Ambiguous & $\begin{array}{l}\text { Taale and } \\
\text { Kyeremeh (2016) }\end{array}$ \\
\hline Home Business & $\begin{array}{l}\text { Kenya } \\
\text { India }\end{array}$ & $\begin{array}{c}\text { Effects of household entrepreneurial } \\
\text { aspiration on WTP for reliable } \\
\text { electricity }\end{array}$ & $\begin{array}{l}\text { Bidding game } \\
\text { Double-bounded } \\
\text { dichotomous choice } \\
\text { experiment }^{5}\end{array}$ & Positive & $\begin{array}{l}\text { Abdullah and } \\
\text { Jeanty (2009) } \\
\text { Gunatilake (2012) }\end{array}$ \\
\hline
\end{tabular}

\footnotetext{
4 In a bidding game, the bid is increased until a respondent answers 'no' (Gunatilake, 2012).

${ }^{5}$ In this method, respondents are presented with a panel of values and response categories that have been arranged into a matrix; they are then asked to mark the degree of confidence that they feel about paying or not paying for the amounts listed in the choice matrix (FAO, 2000).
} 

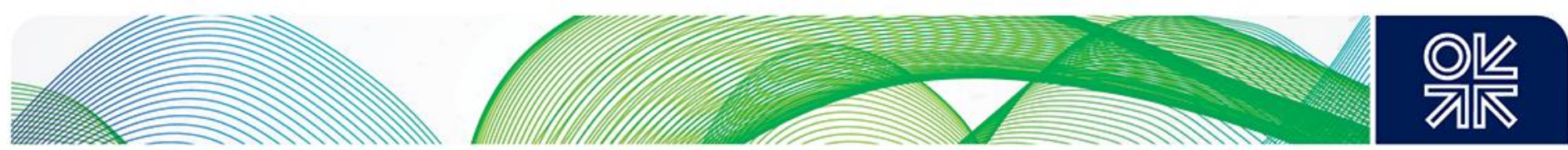

\section{B. Cultural and behavioural determinants}

While the socioeconomic factors that correlate with household WTP have been studied extensively, there continue to be large gaps in the research on behavioural components of consumer preferences and WTP, as it relates to the energy sector in LIDCs. Existing literature has begun to include studies on the influence of factors such as trust, inattention, and information biases. In particular, nascent work on the role of trust has begun to consider the ways in which a lack of trust - where consumers may not believe that an electricity service will be provided or improve - impacts the valuation of electricity. This mentality is potentially shaped by intergenerational distrust and the historical precedence of politicians failing to deliver on electoral promises of universal and reliable access. ${ }^{6}$ Abdullah and Mariel (2010) find, for example, that the level of trust in the electricity authority can account for variation in WTP values, while Townsend (2000) discusses the prevalence of lower WTP within countries that face gaps between price increases and improvements in service quality. In contrast, in a study in Ghana, Amoah et al. (2017) find a reverse effect:

\footnotetext{
'[individuals] who trust the government are currently not willing to pay more for an improved electricity service because they believe the promises made to them by politicians that they would be provided with an improved service without them having to pay more'.
}

Most recently, Blankenship et al. (2019) find, in a randomized experiment in India, that survey respondents with greater social trust are willing to pay more for additional hours of electricity per day, while delays in service improvements and low community support for price reform decrease WTP. To the best of my knowledge, there are no other studies that look at this relationship. Given the lack of empirical work on the role of trust in influencing household WTP for improved electricity services, it is difficult to make a directional claim beyond a hypothesis that trust is an important determinant of WTP for reliable power. On the one hand, negative reciprocity or a lack of trust and public confidence in the government or relevant service providers can drive a low WTP for improved electricity services (Lal, 2005) or even a widespread practice of theft or non-payment of bills (Golden and Min, 2012). On the other hand, high trust in government may drive either low WTP - if the belief in political promises is strong, as in Ghana, (Amoah et al., 2017) - or increases in WTP - if the public is confident that higher prices will improve service. These considerations are further complicated by dynamics such as cultural acceptance or rejection of private electricity providers, and beliefs about who should bear the responsibility for electricity provision (see Figure 1).

Cognitive biases such as an information bias or attention bias ${ }^{7}$ may also affect WTP. For example, Bringeus and Karlsson (2016) find a clear positive relationship between awareness of the existence of electricity subsidies and support for price reform. Moreover, Garg et al. (2016) find in a set of attitude surveys conducted in Rajasthan that citizens are generally unaware of, or misinformed about, the current financial status of distribution companies and only half were aware of the existence of subsidies. ${ }^{8}$ This misinformation or unawareness in relation to existing government support and subsidies has the potential to, again, strongly correlate with trust and its impacts on support for price reform. For example, Alkon and Urpelainen (2018) found that political trust in the government predicts

\footnotetext{
${ }^{6}$ For example, in an older study on the water sector (which can face similar distributional challenges to the electricity sector in developing settings) Altaf et al. (1993) find that WTP for systems with improved reliability was lower among households that were already connected to the piped water system. This led the authors to hypothesize that their low valuation may result from historical precedence and scepticism toward the overall system.

${ }^{7}$ In cognitive psychology literature, an information bias can be classified as a form of bias that involves a distorted evaluation of information. Similarly, in economics literature, attentional bias is defined as the amount that an individual's preferences deviate from his/her preferences under full attention. Thus, if consumers are well informed, they will have little or no attentional bias if they do not care about the information they learn.

${ }^{8} 32$ per cent of households believe that distribution companies can cover their costs entirely by customer revenues, 54 per cent of households believe costs are covered through a combination of revenues and government support, and of this group, 55 per cent believe the government provides less than 20 per cent of total costs - whereas the actual figure is closer to 50 per cent of total costs (Garg et al., 2016).
} 

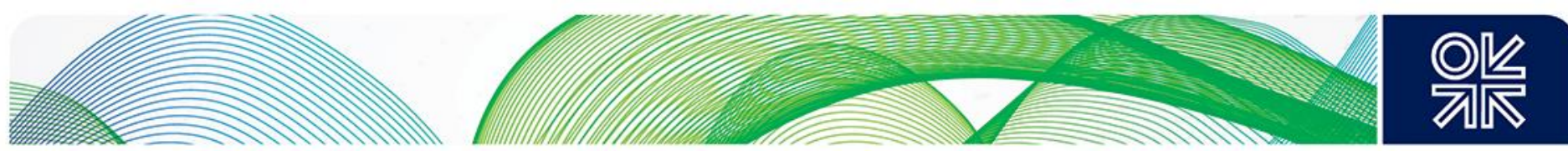

Indian farmers' support for energy subsidy reform. The few findings that exist point to the potential presence of widespread inattention or misinformation about the level of government support already provided to distribution companies. This begs the question of how the provision of more accurate and accessible information about subsidies and costs may affect consumer perception of, and trust in, service providers, and consumers' subsequent WTP and support for price reform toward cost-reflective tariffs.

Figure 1: Average WTP, based on provider expected to be responsible for electricity

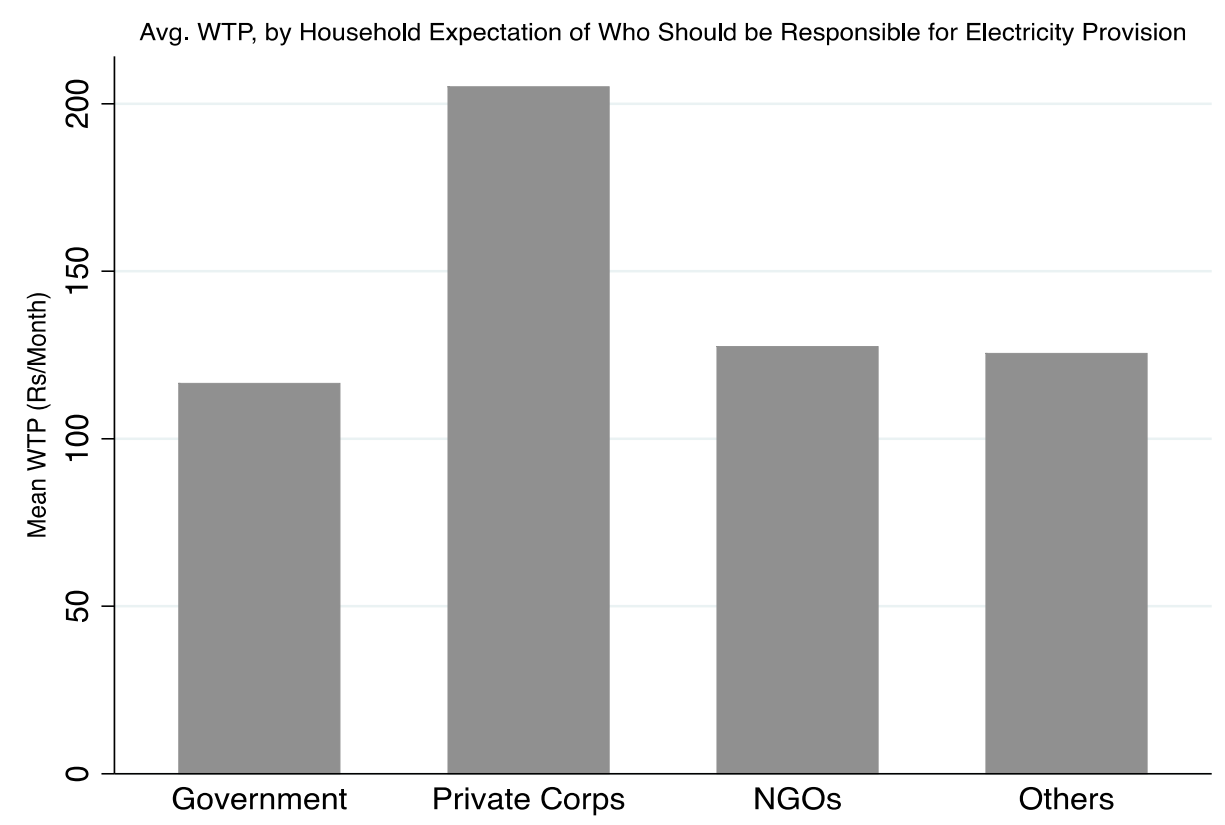

This figure was generated using the ACCESS data (Aklin, 2017).

The horizontal axis is generated based on a variable in the questionnaire that asks:

'Which of the following should be in charge of the supply of electricity in your village?'

While existing literature on the impacts of information, attention, and trust on WTP and behaviour is sparse - particularly within the context of energy and electrification - the research area is nonetheless active and growing. Table 2 represents a small sample of the projects listed in the American Economic Association (AEA) Randomized Control Trials (RCT) Registry that are beginning to fill the gaps in this research agenda. 

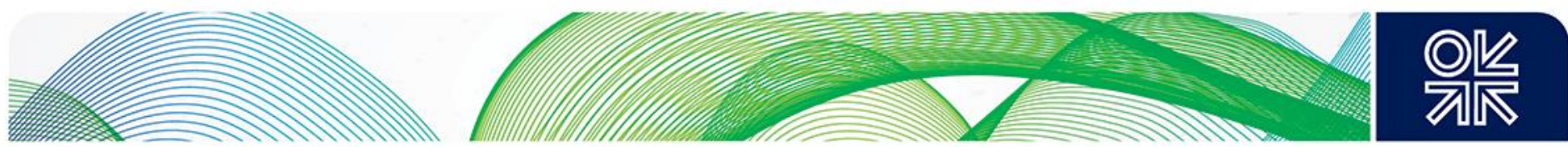

Table 2: Behaviour and Energy Projects in AEA RCT Registry (2014-2018)

\begin{tabular}{|c|c|c|c|c|}
\hline Cognitive Bias & Country & Proposal Description & Status & Source \\
\hline Information & Senegal & $\begin{array}{l}\text { This proposal, titled 'Senegal Solar Lights } \\
\text { Quality Assurance and Guarantee Impact } \\
\text { Evaluation', aims to better understand } \\
\text { consumer behaviour and difficulty } \\
\text { differentiating between good and bad quality } \\
\text { technologies. In particular, the study } \\
\text { proposes to test whether pilot informational } \\
\text { interventions help close information gaps and } \\
\text { increase demand for higher-quality products. }\end{array}$ & $\begin{array}{c}\text { Started, } \\
\text { March } \\
2018\end{array}$ & $\begin{array}{r}\text { Coville and } \\
\text { Reichert } \\
(2017)\end{array}$ \\
\hline Awareness & Senegal & $\begin{array}{l}\text { This proposal, titled 'Senegal Behavior } \\
\text { Change and Solar Lights Evaluation', aims to } \\
\text { carry out a behaviour change campaign that } \\
\text { relies on a combination of radio clip } \\
\text { broadcasting and community outreach on per } \\
\text { capita cost savings to assess effects on } \\
\text { consumer awareness, understanding, and } \\
\text { demand for solar lighting. }\end{array}$ & $\begin{array}{l}\text { Completed, } \\
\text { May } 2016\end{array}$ & $\begin{array}{r}\text { Coville and } \\
\text { Reichert } \\
(2017)\end{array}$ \\
\hline Attention & Kenya & $\begin{array}{l}\text { This proposal, titled 'Behavioral determinants } \\
\text { of household energy efficiency in a } \\
\text { development context', aims to study how } \\
\text { limited attention, product uncertainty, and } \\
\text { mental accounting affect consumer } \\
\text { perceptions of energy saving and technology } \\
\text { adoption. In particular, the study includes two } \\
\text { interventions: (1) encourage consumers to } \\
\text { have a greater level of attention by calculating } \\
\text { expected savings from an energy-efficient } \\
\text { appliance and (2) randomize access to a trial } \\
\text { appliance for a week before making } \\
\text { purchasing decisions. }\end{array}$ & $\begin{array}{c}\text { Started, } \\
\text { November } \\
2017\end{array}$ & $\begin{array}{r}\text { Berkouwer } \\
\text { and Dean } \\
(2017)\end{array}$ \\
\hline Information & Namibia & $\begin{array}{l}\text { This proposal, titled 'Improving Payment } \\
\text { Behavior for Water in Rural Namibia', while } \\
\text { specifically relevant to water, has many } \\
\text { parallels to the energy sector in LIDCs. In the } \\
\text { first stage of the project, the researchers are } \\
\text { analysing a data panel on payment behaviour } \\
\text { of private customers in the rural areas of the } \\
\text { country. Next, the researchers conduct } \\
\text { telephone interviews to better understand } \\
\text { reasons for non-payment and then pilot } \\
\text { targeted SMS messages to test two } \\
\text { behaviourally informed interventions around } \\
\text { building consumer commitment strategies for } \\
\text { payment. }\end{array}$ & $\begin{array}{l}\text { Ongoing, } \\
\text { Started } \\
\text { November } \\
2014\end{array}$ & $\begin{array}{l}\text { Rockenbach } \\
\text { et al. (2015) }\end{array}$ \\
\hline
\end{tabular}



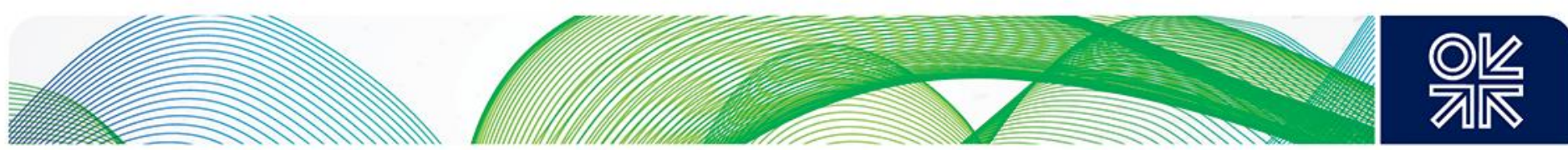

An addition to this research agenda could include the design of an RCT with different informational primes $^{9}$ that aimed to separate the effects of trust, misinformation, or inattention on WTP. The results from the cited literature and ongoing experiments already have clear policy implications: building trust and greater credibility in electricity supply institutions, such as distribution companies, can impact households' perception of price reform, increase WTP, and reduce delinquent payment behaviour. This can be achieved in a number of ways. For example, state governments in Maharashtra and Bihar have started to experiment with having their distribution companies publicly announce service guarantees and 'condition the quality of electricity supply on recent payment rates' (Blankenship et al., 2019). Similarly, policies can be designed that incorporate behavioural 'nudges' 10 and social signalling mechanisms to increase community cooperation. For example, Tata Power-Delhi Distribution Limited (TPDDL) - a large distribution company jointly owned by the Government of Delhi and Tata Power Co. - has applied a scheme in the peri-urban slums of Northern Delhi that successfully reduced electricity theft by marking public electricity meters with different colours that implied whether a community member had paid their bill or not (Sinha, 2017). Figure 2 presents a number of policy interventions and nudge design mechanisms that have already been implemented or hold the potential - based on findings from existing literature - to enhance trust and diminish information asymmetries in electricity supply. Boxes 1-3 further highlight practical case studies of initiatives that have been applied in India, Kenya, and in Brazilian favelas, respectively, to build social trust and contracts between community members and electricity distributors, thereby improving payment behaviour and decreasing theft. It would be interesting for future research to carry out WTP analyses in areas where such community trust-building reforms have been applied.

\footnotetext{
${ }^{9}$ As an example, a detailed research experiment proposal with informational primes in the Indian context is laid out in (Rahnama, 2018) under 'Research Proposal for Future Work'.

10 Thaler and Sunstein (2008) argue for the implementation of a 'choice architecture' form of policy, in which individuals are 'nudged' toward welfare-maximizing outcomes through a combination of strategies that derive from studies in behavioural economics and cognitive science, such as the proper framing of choices and provision of appropriate default options.
} 

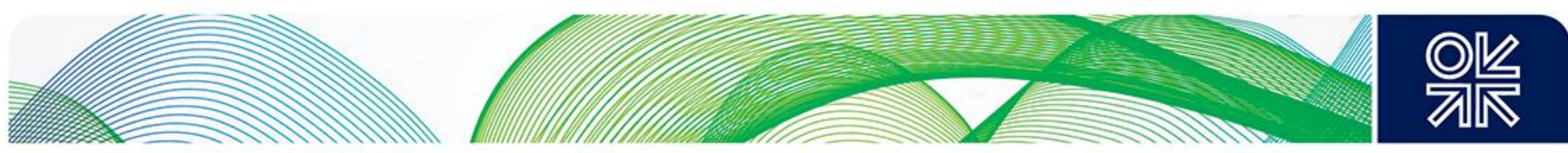

Figure 2: Electricity theft, attitudes toward tariff hikes, and bill payment strategy design Underlying Cause Design Tactic Implementation

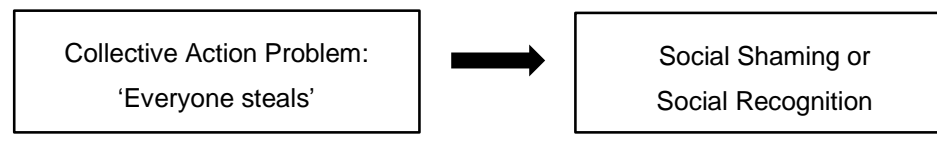

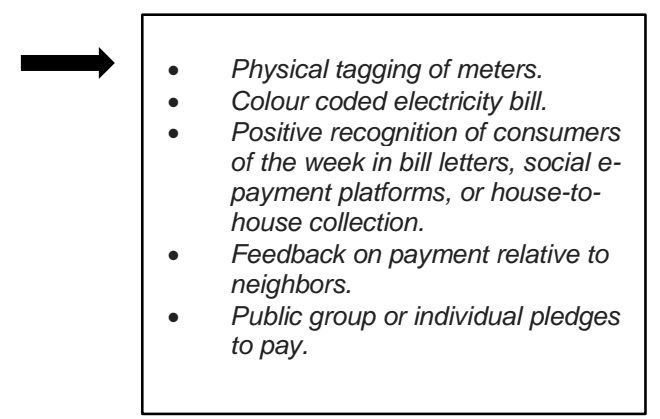
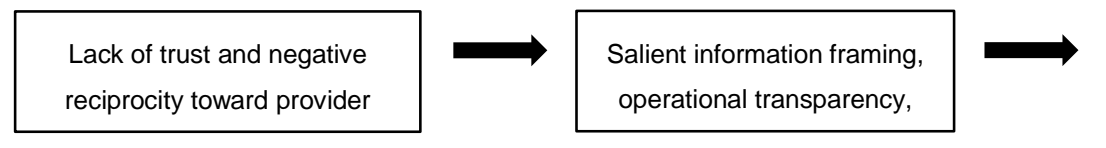

- Made price notches salient in bills.

- Employ local sales network with trusted (female) members of a community.

- $\quad$ Provide a try-before-you-buy option for testing a service and building trust, with the potential experience of loss aversion when the trial period is over.

- Simplified information on relationship between bill payment and electricity reliability.

- $\quad$ Text messages before planned outage.

Misinformation or inattention bias about tariff or subsidy

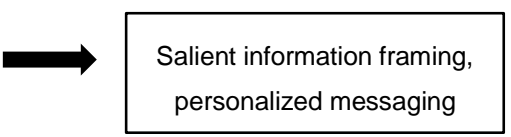

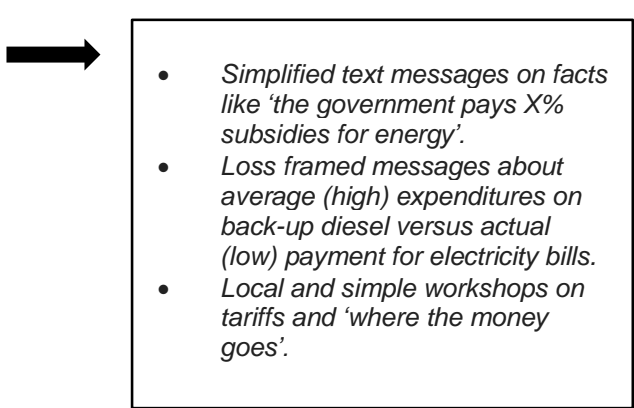

Source: Author's own compilation. 

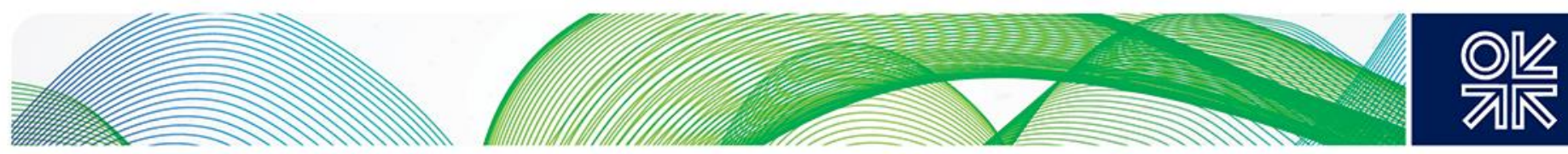

\section{Box 1 \\ Tata Power DDL: working with women to tackle electricity theft in New Delhi's slums}

One of the main causes of an annual ten billion-dollar loss in revenue for India's power companies (together with the widespread incidence of electricity theft) is the refusal of slum dwellers to pay their bills. When company officials try to enforce bill payment, they often face mobs and are beaten, tied up, urinated on, or even murdered. To address this longstanding social challenge, Tata Power Co.'s joint venture with the state government in Delhi has created a model that has significance beyond India in its effectiveness. In particular, in the early phase of piloting this model, TPDDL hired women who lived in 223 slums in the northern and north-western parts of Delhi to serve as local ambassadors for the company, calling them Abhas (which means 'light' in Sanskrit). Today, this force has grown to 841 wives, mothers, and young women who 'go around slums, knocking on neighbours' doors and persuading, coaxing, cajoling, and nagging them to pay their bills'. As a last resort, if these tactics do not work and no payment results, then the power is disconnected. Over the last five years, this initiative has, at minimal cost, increased revenue by 183 per cent and over 56,000 previously free-riding households have become bill-paying, bona fide customers. Given that slum residents prefer to interact with women from their own communities, these Abhas have gained the support of community leaders: 'the scarcity of resources in slums ensures an interdependence among residents that means they are more likely to listen to one of their own ... the social fabric is much tighter in slum clusters ... an outsider will never match up to having this level of influence'.

Given the enormous success of this community capacity-building programme, other rival companies have started to mimic the initiative in their own service areas. For example, BSES Delhi, which is a rival to TPDDL, worked with 40 women this year to pilot a scheme in which the resident women distributed bills and collected payments from neighbours. The World Bank is now testing similar initiatives in Jamaica and Kenya, where challenges of electricity theft are also rampant, and is further considering expanding these pilots to other countries in sub-Saharan Africa.

Source: Shrivastava (2017)

\section{Box 2}

\section{Condesa slum electrification: community and trust-building in Nairobi, Kenya}

In just one year, Kenya Power went from a figure of 5000 to 150,000 households gaining formal electricity connections; this was largely due to a number of core community-based initiatives. In particular, two main approaches accounted for a significant portion of this turnaround in the company's operations:

1. Kenya Power adjusted its business model to undertake more of a community-based approach in the slums, which involved working with local community members and leaders to market the benefits of legal connections (such as safety, reliability, and affordability). Moreover, Kenya Power decided against applying a punitive approach, which meant they no longer took down illegal connections, but tried instead to educate consumers on the benefits of legal connections.

2. Kenya Power strengthened its collaboration with the Kenya Informal Settlements Improvement Project, which is a World Bank supported programme that holds a strong reputation in the urban slums. By creating strong connections with local partners, the company was better able to segment the slum areas and create more targeted and area-specific approaches.

As a result of this approach, many of the former vendors of illegal electricity have joined the legal business of selling Kenya Power chips to consumers, who largely use a pay-as-you-go scheme and now spend less money than they previously spent on illegal electricity. 

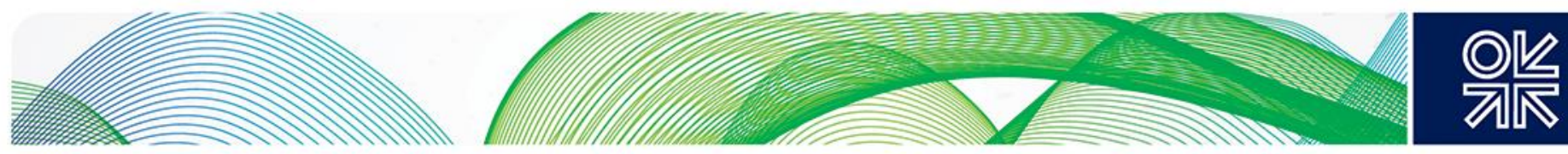

\section{Box 3}

\section{Light: rebuilding trust in the favelas of Rio de Janeiro, Brazil}

In the last several decades, a number of the favelas of Rio de Janeiro have been overtaken by the drug trade and drug lords (who carry out territorial practices), preventing residents from accessing basic services such as water, sanitation, healthcare, or energy. In particular, with regards to energy access, residents have often had to turn to alternative methods of obtaining access, including stealing directly from overhead cables. This pervasive practice of accessing the electricity supply has caused Light, the fourth-largest Brazilian power company in terms of client base, to cope with 64.1 per cent non-technical losses and a rate of 90.4 per cent defaults on bill payment. Light faced an environment of weak social contracts and a complete lack of mutual trust between the power distribution company and the population of the favelas. Consequently, the company, in partnership with the federal government, took a multifaceted approach to try and reverse this unsustainable trend.

1. Light worked with the federal government to establish regulatory incentives targeted at improving the affordability of energy bills and it also invested in the development and installation of new electricity measurement equipment that aimed to overcome future theft from the overhead cables.

2. The company invested resources in rebuilding the broken social contract with the consumer base; these included providing more efficient and cheaper home appliances, curating economic and social opportunities, entrepreneurship training, and access to micro-financing.

As a result of these actions, the average levels of non-technical losses and of defaults in these areas have dropped spectacularly to 11.1 per cent and 1.5 per cent, respectively. Moreover, the company has implemented other recent multi-system innovations, such as recycling waste in exchange for discounts on electricity bills. This multi-systemic and holistic approach to rebuilding trust in a community in which it was formerly broken has been highly effective in transitioning the company toward a sustainable and successful business model.

Source: Lins (2014)

\subsection{Impacts of power quality and reliability}

This paper ultimately contributes to a growing literature on the impact of low reliability on consumer WTP, as well as the economic and welfare consequences of low power quality in developing countries. A review of definitions is useful prior to diving into the literature. Reliability is defined in a number of ways, each of which incorporates several key aspects. These include: the number of customers, the connected load, the duration of the interruption measured (in seconds, minutes, hours, or days), the amount of power (kVA) interrupted, and the frequency of interruptions. The four most common indices for measuring reliability, as defined in IEEE Standard 1366 include SAIFI, SAIDI, CAIDI, and MAIFI:

1. SAIFI: or System Average Interruption Frequency Index, is the average frequency of sustained interruptions per customer over a predefined area.

2. SAIDI: or System Average Interruption Duration Index, is the sum of the restoration time for each interruption event and is divided by the total number of customers.

3. CAIDI: or Customer Average Interruption Duration Index, is the average time needed to restore service to the average customer per sustained interruption.

4. MAIFI: or Momentary Average Interruption Frequency Index, is the number of momentary interruptions (resulting from each single operation of an interruption device) divided by the total number of customers served.

While these indices are informative on a technical level, there are nonetheless many debates about how comparable they are across geographies with immense social differences that can affect 

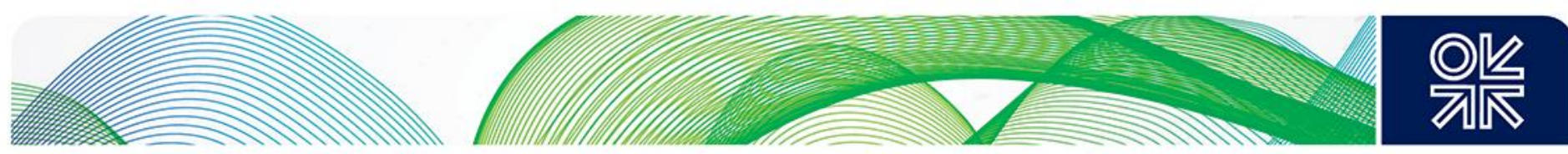

interpretations of the inputs and outputs of calculations (Kueck, 2005). For example, Harish et al. (2014) argue that such conventional measures fail to monitor reliability in the holistic ways that are necessary in the rural Indian context (as well as in other low-income countries) where outages (scheduled and unscheduled load shedding) are caused by a mixture of complex demand side, local capacity, and political economy factors (Gertler et al., 2017). Each of these measurements and the reliability definitions that they register - from frequency of outages, duration of outages, and restoration wait time - may manifest differently into the consumer psyche and subsequent WTP. For example, even if outages are frequent, consumers may be willing to pay more if they are guaranteed short durations or quick restoration times. Or, in contrast, even if the duration time of an outage is long, consumers may be willing to pay more for electricity if they are informed in advance, allowing them to manage their expectations. This variability in consumer preferences and WTP for reliability across its different forms of measurement is not well understood and is a highly valuable area for future research.

While there are a few studies that have examined attributes influencing WTP for reliable electricity, most of these existing papers have focused specifically on 'green' energy attributes in high- and middleincome countries (Goett et al., 2000; Hensher et al., 2014). Moreover, of the few studies that have examined different effects of poor reliability and power outages in low-access and income settings, most have focused on firm-level, rather than household-level, impacts (Steinbuks and Foster, 2010; FisherVanden et al., 2015). As discussed in Lee et al. (2017),

'[there is] almost no data on even the most basic patterns of outages in developing countries ... we need more research on the economic consequences of different levels of power quality, as well as the potential gains from investing in improvements' [at both a firm and household level].

Better understanding of the sources and outcomes of poor reliability - from supply-side factors like generation capacity, demand-side factors like surpassing load capacity, and political economy factors like subsidy traps and theft - holds important implications for different forms of political, economic, and technological solutions (Gertler et al., 2017; McRae, 2015; Lee et al., 2017).

In spite of the lack of studies, this growing literature nonetheless points at interesting early findings. Three studies in India find a significant relationship between electricity reliability, demand, and WTP:

- Khandker et al. (2012) find that a one-hour increase in average availability of electricity at the village level increases the rate of household electricity adoption and of consumption by 2.4 per cent and 14.4 per cent, respectively.

- Moreover, in one of the few studies in India that used choice experiments and contingent valuation methods ${ }^{11}$ to analyse consumer responses to different outcome measures for reliability in Madhya Pradesh, Gunatilake (2012) found a WTP (per month) of 106 Rs for 24 hours of electricity supply (as compared to 38 Rs for 12 hours); 243 Rs for the highest quality of service; 38 Rs for improved customer service; and 45 Rs for accurate billing practices.

- These implications extend to the off-grid sector as well. In a study carried out in Uttar Pradesh, Graber et al. (2018) find that consumers who have been exposed to microgrids report, at a very high level of statistical significance:

- $\quad$ a greater satisfaction with reliability as compared to consumers exposed to both the grid and microgrid simultaneously;

have a higher WTP for reliability attributes;

have a higher WTP for electricity that is delivered when expected, rather than 24 hours of electricity;

generally place a higher value on electricity that is reliable during evening hours.

\footnotetext{
${ }^{11}$ Contingent valuation and other choice experiment methods for measuring WTP are outlined briefly in Section 4.
} 

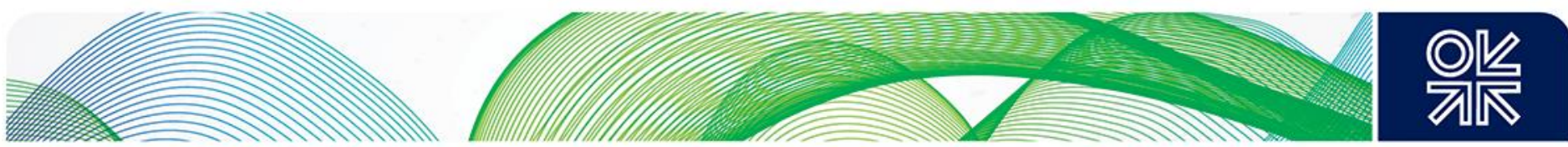

A number of studies in sub-Saharan Africa report similar findings. In Nigeria, Oseni et al. (2017) find that engagement in self generation is positively correlated with WTP for reliability and that households are more concerned about the total duration of outages than the separate impacts of outage frequency when assessing their WTP. Similarly, in Ghana, Taale and Kyeremeh (2016) find that prior notice on outages is positively correlated with WTP for reliable electricity, while in rural Kenya, Abdullah and Mariel (2010) find a WTP of 50Ksh to avoid outages, using a contingent valuation method.

Table 3: Literature on reliability measures and WTP

\begin{tabular}{|c|c|c|c|c|c|}
\hline Supply Source & Country & Important Attributes & Study Method & $\begin{array}{l}\text { Sample } \\
\text { Size (HH) }\end{array}$ & Source \\
\hline Grid & India & $\begin{array}{l}\text { General availability of electricity } \\
\text { increases } \mathrm{HH} \text { adoption by } 2.4 \% \text {. }\end{array}$ & $\begin{array}{l}\text { Household } \\
\text { survey data and } \\
\text { maximum } \\
\text { likelihood probit } \\
\text { model }\end{array}$ & 41,554 & $\begin{array}{r}\text { Khandker et al } \\
(2012)\end{array}$ \\
\hline Grid & India & $\begin{array}{l}\text { Higher WTP for } 24 \text {-hours of } \\
\text { electricity, highest quality of service, } \\
\text { improved customer service and } \\
\text { maintenance, and accurate billing } \\
\text { practices. }\end{array}$ & $\begin{array}{l}\text { Bidding game } \\
\text { Dichotomous } \\
\text { choice and probit } \\
\text { model }\end{array}$ & $200^{12}$ & $\begin{array}{r}\text { Gunatilake } \\
\text { (2012) }\end{array}$ \\
\hline Microgrid, Grid & India & $\begin{array}{c}\text { Higher WTP for reliability attributes, } \\
\text { electricity that is delivered when } \\
\text { expected (rather than } 24 \text { hours), and } \\
\text { electricity that is reliable in the } \\
\text { evening. }\end{array}$ & $\begin{array}{l}\text { Choice } \\
\text { experiment and } \\
\text { mixed logit model }\end{array}$ & 220 & $\begin{array}{r}\text { Graber et al } \\
(2018)\end{array}$ \\
\hline Grid & Nigeria & $\begin{array}{l}\text { Higher concern about total length of } \\
\text { outages (outage) time than separate } \\
\text { impacts of frequency and duration } \\
\text { when making WTP decision. }\end{array}$ & $\begin{array}{l}\text { Revealed } \\
\text { preference }\end{array}$ & 1,376 & $\begin{array}{l}\text { Oseni et al } \\
(2017)\end{array}$ \\
\hline Grid & Ghana & $\begin{array}{l}\text { Prior notice on outages positive } \\
\text { correlated with WTP. }\end{array}$ & $\begin{array}{c}\text { Household } \\
\text { survey - stated } \\
\text { preference CVM }\end{array}$ & 950 & $\begin{array}{r}\text { Taale and } \\
\text { Kyeremeh }(2016)\end{array}$ \\
\hline Grid & Kenya & High WTP for avoidance of outages. & $\begin{array}{l}\text { Double-bounded } \\
\text { dichotomous } \\
\text { choice } \\
\text { experiment }\end{array}$ & 200 & $\begin{array}{l}\text { Abdullah and } \\
\text { Mariel }(2010)\end{array}$ \\
\hline
\end{tabular}

\footnotetext{
12 The paper did not provide an exact sample size; this is therefore an estimate based on the following: 'Only GPs (Gram Panchayat) having 200-500 households were considered for drawing a sample of households for this study in order that smaller-sized and larger-sized GPs were avoided. Only 455 GPs met this right-size criterion out of 1013 GPs. From these, 40 GPs were randomly selected, using random number tables. These 40 GPs consisted of 110 villages; however, populations within some villages were too large to be included in the sample due to difficulties in provided logistics for conducting the survey. Therefore, samples were restricted to 76 villages that had at least 20 per cent of the population of their respective GPs. In each GP, 50 households were selected' (Gunatilake, 2012).
} 

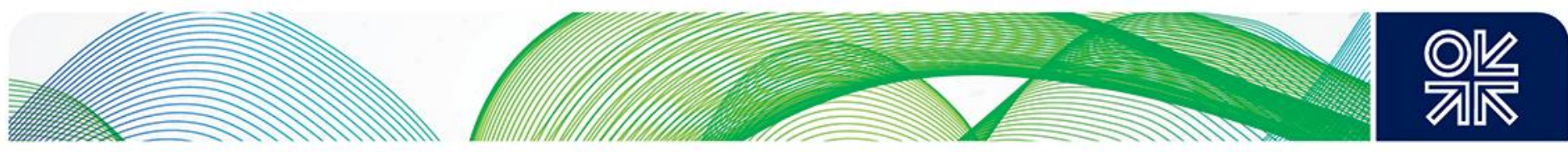

The aforementioned findings on a high WTP for prior notice on outages and their duration may indicate a high value being placed on expectations: households want to be able to perceive and prepare for outages before they happen, such that they can manage their needs around the outage. A new study in Indonesia has considered this in areas where the grid is unreliable and electricity users experience a higher rate of unavailability of electricity than is indicated by the SAIDI and SAIFI values reported by the utility. As a result, Reinders and Reinders (2018) proposed new indices called the Perceived (P) SAIDI and SAIFI, which are based on the perceived frequency and duration of outages experienced by users. These are considerably different from the utility-reported values. Variability in consumers' memories and cognitive perception in areas where low reliability exists as a part of daily life may have significant impacts on WTP and is a valuable area for future work. Table 3 summarizes the core findings in this literature across both rural and urban settings in India and sub-Saharan Africa.

The studies cited above have impacted policymaking in a number of ways. For example, the results of the Gunatilake (2012) study with the Asian Development Bank (ADB) have influenced a large-scale distribution improvement project - the Madhya Pradesh Energy Efficiency Improvement Investment programme - by highlighting the value that consumers place on attributes like accurate billing practices and high-quality power, rather than simply hours of supply. Similarly, the Abdullah and Mariel (2010) paper discussed different ways in which enhanced understanding of households' preferences toward electricity reliability can influence targeted product and service design by utility companies. Lastly, findings such as those in Taale and Kyeremeh (2016) have led some companies and policymakers to experiment with text message notifications about scheduled outages. For example, the Indian Ministry of Power launched an app called Urja Mitra in 2016; this disseminates outage information to consumers across India through SMS, email, and push notifications (SCC India, 2017). Moreover, Prayas Energy Group, based out of Pune in India, launched a programme called the Electricity Supply Monitoring Initiative (ESMI), wherein several hundred electricity supply monitors were installed in households, farms, and small commercial establishments throughout the country. These ESMs record voltage by the minute at the location of installation and transfer the data to a central server, which makes it publicly available on watchyourpower.org. This allows consumers and CSOs to use the data to verify if the villages electrified through India's rural electrification programme actually receive their mandated six hours of daily supply, and also to compare supply quality in different regions of the country. These ESMs have already enabled the collection of interesting data: in January 2018, 52 per cent of ESMI locations suffered from outages for 15+ hours; 35 per cent had over 30 interruptions, each of over 15 minutes long; and 28 per cent of locations experienced average daily outages of 30 minutes and over during evening hours (Prayas Energy Group, 2018). Future evaluative research on the effects of SMS outage notifications and citizen-focused e-monitoring initiatives on consumer trust and WTP would be valuable.

\section{India case study}

Drawing insight from the aforementioned existing literature, I use survey data from six states in India to conduct a descriptive analysis of the socioeconomic, behavioural, and technical factors that correlate with variations in household valuation of electricity access and reliability in rural municipalities. In particular, I look into a subset of unique behavioural and technical variables within the survey and examine the ways in which they interact with estimates of WTP. With regards to behavioural factors, the survey asks a set of questions on theft - which will be elaborated on Section 3.3 - that can serve as proxies for measures of social trust or mistrust (Blankenship et al., 2019). The aim of this illustrative case study is not to provide causal evidence, but rather general insights into the potential factors that explain energy-poor households' decision-making and WTP for a spectrum of electricity services. Using this survey, I provide a particular unique contribution to the existing literature by disaggregating the analysis on socioeconomic, behavioural, and technical determinants of WTP, on the basis of different combinations of household electricity connections, rather than by simply focusing on electricity from a single source, such as the grid. A brief description of the data is outlined in the following section. 

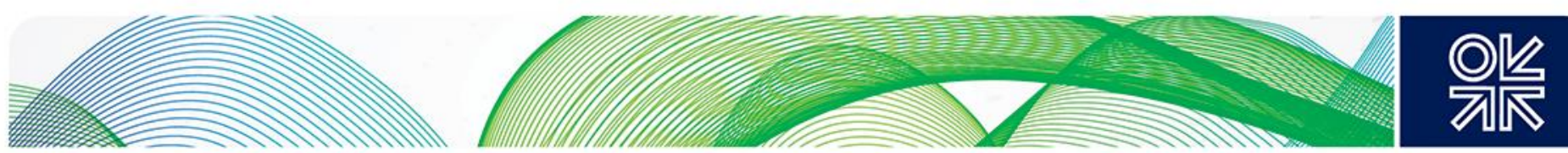

\subsection{ACCESS: access to clean cooking, energy, and electricity - survey of states in India}

ACCESS is a comprehensive and statistically representative dataset on energy poverty in rural India; it includes information on access, subjective satisfaction, and policy preferences for 8,565 households from 714 villages across six states in India (Bihar, Jharkhand, Madhya Pradesh, Uttar Pradesh, Odisha, and West Bengal). The sampling of this data was conducted in such a way as to ensure adequate representation of rural areas across the six states, and this level of representation was cross-validated with household and village data from the National Sample Survey of India and the 2011 Census of India, respectively (Aklin, 2017). I combine the raw household-level and revenue village-level data.

For the basic analysis that follows, I consider the following key questions and variables:

1. How many hours a day is electricity usually available?

2. How many hours is electricity usually available between sunset and midnight?

3. How many hours in the last month has there been no power throughout the day?

4. How many days in a month have you experienced electric equipment suffering from voltage fluctuation?

5. How many days in a month have you experienced voltage that was too low to run appliances?

6. How many of the follow [list of appliances] do you use?

7. Which of the following [in the list of appliances] would you want to use, but are unable to use only because of the limited supply or poor quality of electricity?

8. If you were able to use all the appliances you desire as stated above, how much would you be willing to pay for this overall usage (per month)?

9. For non-electrified households, if you had grid electricity, what would you use it for [list appliances]?

10. How much would you be willing to spend per month for such usage?

11. Has the government conducted awareness campaigns based on solar electricity?

12. Have you heard about microgrids? Have you heard about solar home systems?

13. Who introduced the microgrids? Solar home systems? [Government / NGO / Private Company] 

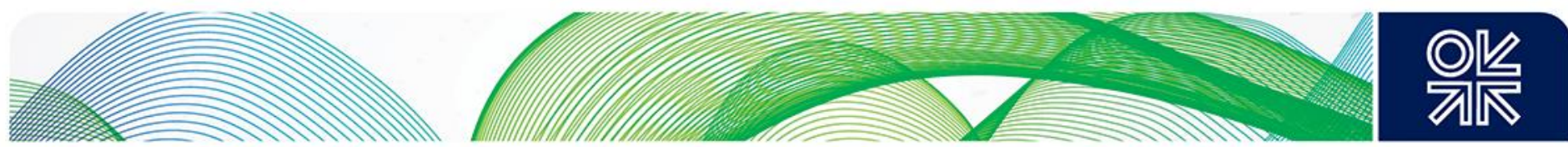

\subsection{Summary statistics}

Table 4 further outlines general summary statistics by connection type (across all states).

Table 4: General summary statistics (by connection type)

\begin{tabular}{|c|c|c|c|c|c|c|c|}
\hline & $\begin{array}{l}\text { Grid } \\
(1)\end{array}$ & $\begin{array}{l}\text { Micro } \\
(2)\end{array}$ & $\begin{array}{c}\text { SHS } \\
(3)\end{array}$ & $\begin{array}{l}\text { Micro/Grid } \\
\text { (4) }\end{array}$ & $\begin{array}{c}\text { Grid/SHS } \\
(5)\end{array}$ & $\begin{array}{c}\text { Micro/SHS } \\
(6)\end{array}$ & $\begin{array}{l}\text { All } \\
(7)\end{array}$ \\
\hline \multicolumn{8}{|l|}{ Demographics } \\
\hline $\begin{array}{l}\text { Age } \\
\text { Male (\%) } \\
\text { Read and write (\%) } \\
\text { No. of children } \\
\text { School children } \\
\text { Number of rooms }\end{array}$ & $\begin{array}{l}42.15 \\
84 \\
77 \\
2.38 \\
1.74 \\
2.93\end{array}$ & $\begin{array}{l}41.76 \\
90 \\
70 \\
2.90 \\
2.09 \\
2.90\end{array}$ & $\begin{array}{l}41.78 \\
89 \\
84 \\
2.77 \\
2.11 \\
3.84\end{array}$ & $\begin{array}{c}38 \\
89 \\
83 \\
3.14 \\
2.29 \\
3.66\end{array}$ & $\begin{array}{c}41.74 \\
87 \\
93 \\
2.90 \\
2.29 \\
4.55\end{array}$ & $\begin{array}{c}44.13 \\
100 \\
100 \\
3.60 \\
3.06 \\
4.81\end{array}$ & $\begin{array}{l}47.75 \\
100 \\
100 \\
4.00 \\
3.25 \\
6.25\end{array}$ \\
\hline \multicolumn{8}{|l|}{ Education } \\
\hline $\begin{array}{l}\text { No schooling (\%) } \\
\text { Fifth standard (\%) } \\
\text { Tenth standard (\%) } \\
\text { Twelfth standard (\%) } \\
\text { Graduate (\%) }\end{array}$ & $\begin{array}{c}27 \\
31 \\
22 \\
11 \\
9\end{array}$ & $\begin{array}{c}33 \\
27 \\
20 \\
12 \\
7\end{array}$ & $\begin{array}{l}17 \\
30 \\
22 \\
17 \\
14\end{array}$ & $\begin{array}{l}23 \\
29 \\
17 \\
20 \\
11\end{array}$ & $\begin{array}{c}7 \\
30 \\
18 \\
23 \\
21\end{array}$ & $\begin{array}{c}0 \\
31 \\
31 \\
19 \\
19\end{array}$ & $\begin{array}{c}0 \\
25 \\
25 \\
25 \\
25\end{array}$ \\
\hline \multicolumn{8}{|l|}{ Occupation } \\
\hline $\begin{array}{l}\text { Agriculture (\%) } \\
\text { Labour (\%) } \\
\text { Business prof. (\%) }\end{array}$ & $\begin{array}{l}53 \\
27 \\
17\end{array}$ & $\begin{array}{l}54 \\
22 \\
22\end{array}$ & $\begin{array}{l}62 \\
11 \\
25\end{array}$ & $\begin{array}{l}23 \\
26 \\
51\end{array}$ & $\begin{array}{c}59 \\
7 \\
32\end{array}$ & $\begin{array}{c}56 \\
100 \\
44\end{array}$ & $\begin{array}{c}50 \\
100 \\
50\end{array}$ \\
\hline \multicolumn{8}{|l|}{ Finances } \\
\hline $\begin{array}{l}\text { Have bank acc. (\%) } \\
\text { Indebted (\%) } \\
\text { Monthly expenses } \\
\text { (Rs) }\end{array}$ & $\begin{array}{c}90 \\
40 \\
5675\end{array}$ & $\begin{array}{c}78 \\
39 \\
6545\end{array}$ & $\begin{array}{c}91 \\
43 \\
6867\end{array}$ & $\begin{array}{c}89 \\
37 \\
7314\end{array}$ & $\begin{array}{c}93 \\
41 \\
8212\end{array}$ & $\begin{array}{c}100 \\
25 \\
11313\end{array}$ & $\begin{array}{c}100 \\
25 \\
12500\end{array}$ \\
\hline Observations & 5640 & 201 & 348 & 35 & 164 & 16 & 4 \\
\hline
\end{tabular}

The results of this table present numeric and percentage averages for core demographic, education, occupational, and financial variables for each combination of electricity connection technology. The results of the last two columns and column (4), in particular, should be taken with a grain of salt, as the sample size is extremely small and not statistically meaningful.

The sample ${ }^{13}$ consists of 5,460 households with a grid connection, 201 households with a microgrid connection, 348 households who own a solar home system, 35 households with both a grid and microgrid connection, 164 households with both a grid connection and solar home system, 16 households with a microgrid connection and solar home system, and a mere 4 households with all three forms of connections. Across all states, the average age of respondents is 42 years old and approximately 85 per cent of respondents are male, which indicates a potential gender bias or skew in the perspectives represented. Moreover, the levels of education range from 408 with no formal schooling, 1356 respondents who have completed lower primary, 2962 who have completed middle school, 2028 who have completed twelfth standard, and 1811 who have a university degree, indicating an overall higher level of education in the majority of the sample. Additionally, 53.77 per cent of the sample works in the agricultural sector, 29.84 in labour, and 14.25 in the professional sector. 

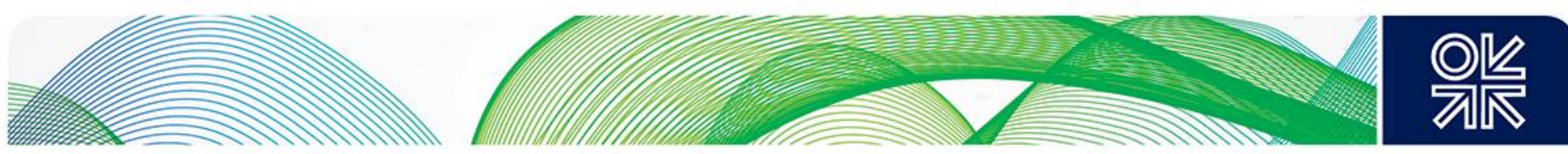

Before diving into a deeper analysis on WTP, the summary statistics above already paint an interesting picture that complements some of the aforementioned literature on socioeconomic and demographic factors that correlate with WTP. The most noticeable trend is that as the number of children, number of school children, and number of rooms in a household increases, so too does the existence of multiple forms of electricity connections. If one hypothesizes, or treats multiple connection-types as some form of proxy for a higher WTP for reliability, then we should expect greater WTP among households with 2-3 forms of electricity connection; a particularly higher level of WTP could also be expected among those households with a greater number of children or rooms in the house (the latter may indicate an overall better financial status).

Table 5 further presents a set of summary statistics on both appliances owned and appliances aspired for among households that are already electrified, as well as WTP, across states for the same combination of connection types.

Table 5: General summary statistics (by connection type)

\begin{tabular}{|c|c|c|c|c|c|c|c|}
\hline & $\begin{array}{c}\text { Grid } \\
(1)\end{array}$ & $\begin{array}{l}\text { Micro } \\
(2)\end{array}$ & $\begin{array}{l}\text { SHS } \\
(3)\end{array}$ & $\begin{array}{c}\text { Micro/Grid } \\
\text { (4) }\end{array}$ & $\begin{array}{c}\text { Grid/SHS } \\
\text { (5) }\end{array}$ & $\begin{array}{c}\text { Micro/SHS } \\
\text { (6) }\end{array}$ & $\begin{array}{l}\text { All } \\
\text { (7) }\end{array}$ \\
\hline \multicolumn{8}{|l|}{ Appliances Owned } \\
\hline Incandescent bulb & 1.81 & 0.48 & 1.10 & 1.46 & 1.83 & 1.13 & 2.50 \\
\hline CFL bulb & 1.26 & 1.28 & 1.91 & 1.83 & 2.34 & 2.10 & 2.50 \\
\hline LED bulb & 0.04 & 0.10 & 0.27 & 0.09 & 0.12 & 0.38 & 0.50 \\
\hline Fans & 1.14 & 0.34 & 1.09 & 1.00 & 1.79 & 0.88 & 1.25 \\
\hline Irons & 0.20 & 0.06 & 0.23 & 0.29 & 0.45 & 0.13 & 0.50 \\
\hline Fridge & 0.09 & 0.02 & 0.13 & 0.09 & 0.24 & 0.06 & 0.00 \\
\hline Television & 0.50 & 0.09 & 0.43 & 0.34 & 0.72 & 0.44 & 0.75 \\
\hline Radio & 0.07 & 0.10 & 0.14 & 0.14 & 0.16 & 0.31 & 0.50 \\
\hline Washing Machine & 0.03 & 0.00 & 0.04 & 0.03 & 0.09 & 0.00 & 0.00 \\
\hline Electric Stove & 0.02 & 0.00 & 0.03 & 0.00 & 0.07 & 0.00 & 0.00 \\
\hline Electric Pump & 0.07 & 0.01 & 0.07 & 0.00 & 0.15 & 0.00 & 0.00 \\
\hline Observations & 5639 & 201 & 324 & 35 & 164 & 16 & 4 \\
\hline
\end{tabular}

\begin{tabular}{|c|c|c|c|c|c|c|c|}
\hline Fan (\%) & 29 & 80 & 52 & 5 & 33 & 88 & 100 \\
\hline Iron (\%) & 25 & 47 & 40 & 46 & 32 & 88 & 100 \\
\hline Fridge (\%) & 24 & 23 & 34 & 32 & 34 & 25 & 0 \\
\hline Television (\%) & 33 & 69 & 54 & 54 & 40 & 75 & 100 \\
\hline Radio (\%) & 11 & 17 & 15 & 27 & 13 & 25 & 100 \\
\hline Electric Stove (\%) & 9 & 16 & 16 & 18 & 19 & 13 & 0 \\
\hline Electric Pump (\%) & 15 & 28 & 28 & 33 & 31 & 50 & 100 \\
\hline Observations & 2941 & 100 & 169 & 22 & 94 & 8 & 1 \\
\hline \multicolumn{8}{|l|}{ Access Statistics } \\
\hline \multicolumn{8}{|l|}{ Avg. Hrs. of Electricity } \\
\hline $\begin{array}{l}\text { Avg. Evening Hrs. } \\
\text { WTP (Rs/Mo) }\end{array}$ & $\begin{array}{l}12.7 \\
3.28\end{array}$ & $\begin{array}{l}4.03 \\
2.40\end{array}$ & $\begin{array}{l}8.37 \\
2.87\end{array}$ & $\begin{array}{l}7.34 \\
2.20\end{array}$ & $\begin{array}{l}10.4 \\
2.69\end{array}$ & $\begin{array}{l}5.88 \\
2.94\end{array}$ & $\begin{array}{l}6.75 \\
2.50\end{array}$ \\
\hline \multirow[t]{2}{*}{ WTP Package (Rs/Mo) } & 140 & 192 & 191 & 253 & 204 & 213 & 200 \\
\hline & 142 & 162 & 151 & 211 & 172 & 243 & 210 \\
\hline
\end{tabular}

In the first section of this table are presented the average number of different types of appliances owned, by each of the electricity connection types. The access statistics, respectively, present the average number of hours a day that electricity is available and the average number of hours that electricity is usually available between sunset and midnight. The appliances aspired present percentages of YES responded to the binary coded variable: which of the following appliances would you want to use, but are unable to use only because of limited supply or poor quality of electricity? The WTP is the average 

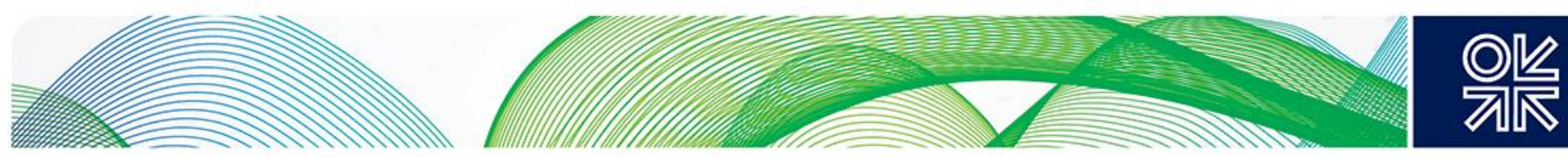

stated WTP per month (in Rs) to be able to use all of these appliances that the households reported aspirations for and the WTP package is the average stated monthly WTP for electricity that is available as per the users' needs and would allow the household to get artificial light for 12 hours/day, use a fan for 8 hours/day, and charge a mobile phone. The results of the last two columns and column (4), in particular, should be taken with a grain of salt, as the sample size is extremely small and not statistically meaningful.

Table 5 reveals some interesting insights about appliance ownership and aspiration patterns by connection type. In particular, most connected households largely own lighting appliances (with most owning CFL bulbs) and fans and the number of each appliance owned seems to increase, on average, with multiple connections. Moreover, among appliances that are aspired for, the appliance that is most consistently in demand across connection types is the television, followed by fans and irons; this potentially indicates a higher emphasis placed on access to entertainment across households than other so-called 'necessity' appliances, like a refrigerator. Within the set of 'access' statistics, the combination of connections that provides the greatest average hours of electricity - aside from the grid - is the grid and solar home connection. Similarly, as hypothesized, there appears to be higher WTP among households that have a combination of appliances. These results, however, should be taken very lightly given a severely underpowered sample (particularly for columns 4,6 , and 7 ). These results are similarly presented in Figure 3.

Figure 3: Appliance ownership and aspiration, by connection type
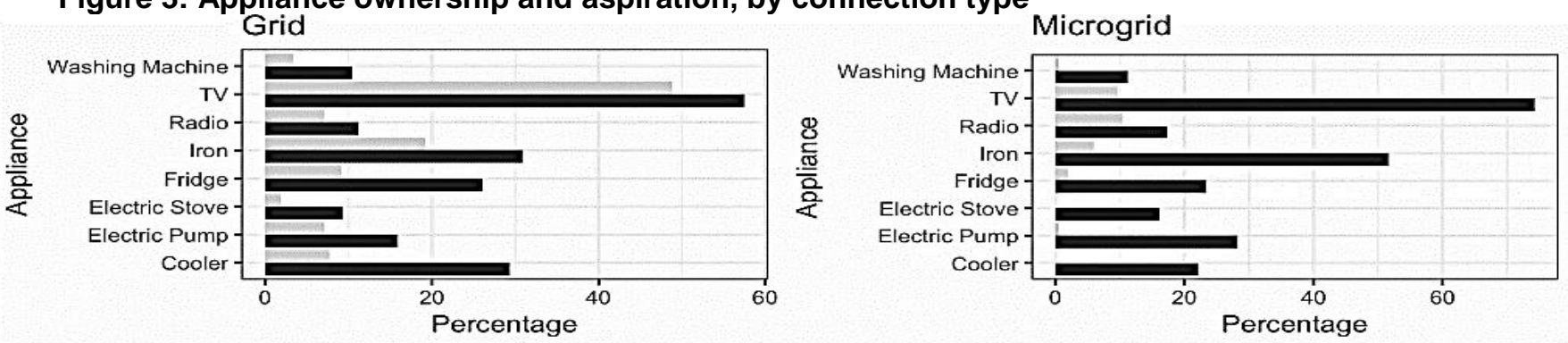

Isolated Solar Systems
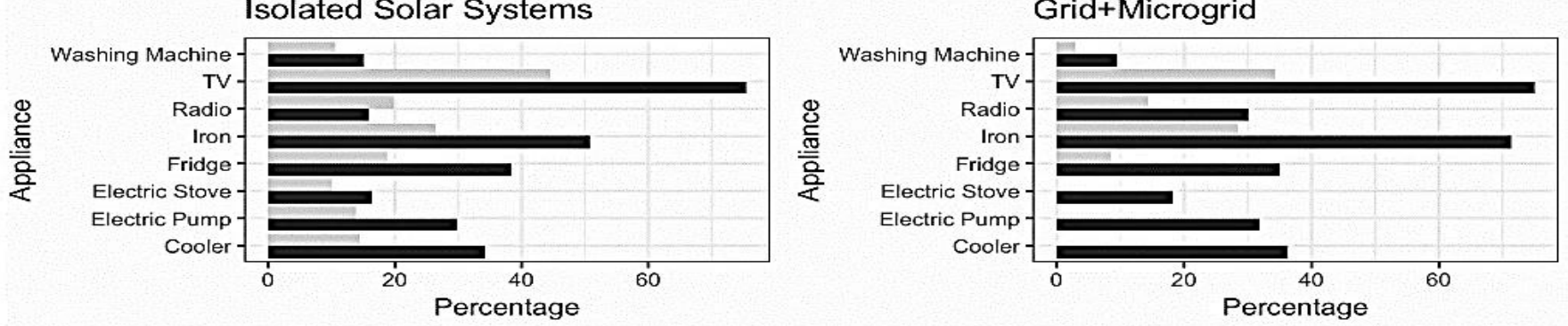

Grid+Isolated Solar System
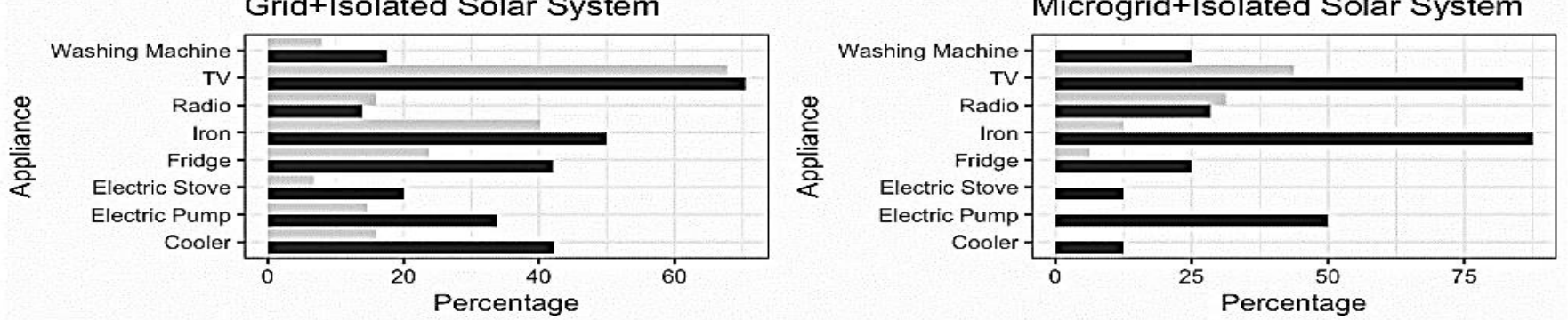

Aspired

Owned

This figure was generated using the ACCESS data (Aklin, 2017).

Proportion of rural households that own versus aspire for higher wattage appliances. 

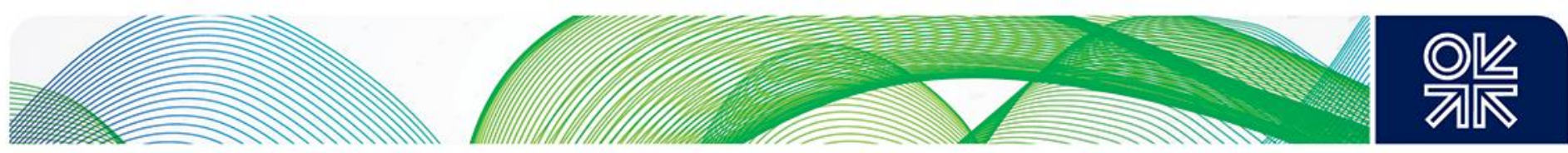

Lastly, among the 2610 households that are not currently electrified with any of the possible sources of connection (grid, microgrid, or SHS), the appliance aspirations are slightly different: 100 per cent of households would use lighting appliances, 99 per cent would use fans, 18 per cent would use irons, 10 per cent would use fridges, 89 per cent would use a television, 8 per cent a radio, 4 per cent a computer, 3 per cent a washing machine, and 14 per cent an electric pump. Moreover, the average WTP for the use of such appliances across these households is 120 Rs per month. Consistent with the previous results, there is extremely high demand for televisions, and also high demand for the particular necessity goods of lighting, fans, and electric pumps (particularly for agricultural labourers).

\subsection{Results and discussion}

In this section I look into a subset of behavioural and technical variables within the survey and examine the ways in which they interact with estimates of WTP. With regards to behavioural factors, the survey asks a set of questions on theft, including dummies on:

(1) whether the respondent believes people steal electricity in the village,

(2) whether the respondent believes that stealing electricity is illegal,

(3) whether the respondent believes that stealing electricity should be stopped.

Drawing from Blankenship et al. (2019), these questions on theft can serve as a sort of proxy for social trust or mistrust. Moreover, the survey also asks some questions on whether the government has conducted awareness campaigns on solar electricity in a village and whether households have heard of microgrids and solar home systems. These awareness questions can be used as proxies for the ways in which information can impact household valuation and WTP for electricity from solar. In Table 6, I present mean summary statistics on various WTP values for households that answer YES to each of the binary questions on theft and awareness versus those that answer NO to the same binary questions.

Table 6: Average WTP, by attitudes toward theft and awareness of solar

\begin{tabular}{|c|c|c|c|c|c|c|c|c|c|c|c|c|}
\hline & \multicolumn{2}{|c|}{ Others Steal } & \multicolumn{2}{|c|}{ Stealing Illegal } & \multicolumn{2}{|c|}{ Stealing Should Stop } & \multicolumn{2}{|c|}{ Gov. Awareness Campaign } & \multicolumn{2}{|c|}{ Heard of Microgrid } & \multicolumn{2}{|c|}{ Heard of SHS } \\
\hline & YES & NO & YES & NO & YES & NO & YES & NO & YES & NO & YES & NO \\
\hline \multicolumn{13}{|l|}{ WTP (Rs/Mo) For: } \\
\hline All desired apps. & 134 & 155 & 141 & 190 & 142 & 140 & 139 & 142 & 175 & 132 & 171 & 106 \\
\hline Grid connection & 605 & 429 & 459 & 457 & 459 & 563 & 351 & 451 & 446 & 447 & 469 & 407 \\
\hline Standard package & 146 & 130 & 132 & 130 & 132 & 117 & 147 & 129 & 132 & 130 & 140 & 116 \\
\hline Electricity (overall) & 128 & 131 & 113 & 202 & 117 & 96 & 132 & 120 & 137 & 115 & 135 & 97 \\
\hline
\end{tabular}

The summary statistics above do not have any causal implications nor do they imply statistically significant differences in mean WTP, but they do reveal interesting patterns: on average, there is, generally speaking, a higher WTP (across the different variables for measuring WTP) among respondents who have heard of microgrids and solar home systems, as compared to those that have not. Moreover, the government awareness campaign on solar indicates a potential impact of informational interventions on household WTP: there is higher WTP for the standard package (of lighting, a fan, and mobile charger) and for electricity overall among households that have experienced the government awareness campaign. Interestingly, there is also a lower WTP for a grid connection among households that received the awareness campaign for solar as compared to those that did not, which may imply some impact of information on community attitude toward solar power. In contrast, the results for questions on theft - which may proxy for social trust or distrust - paint a more puzzling and inconsistent narrative. 

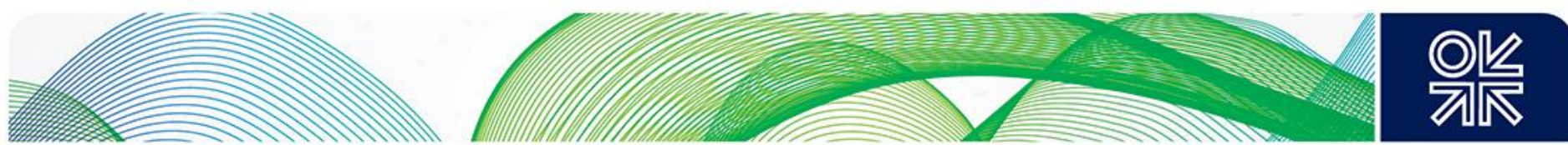

Next, I consider interactions between measures of reliability within the survey and willingness to pay. The panel below in Figures $4 \mathrm{a}$ and $4 \mathrm{~b}$ presents a series of binscatter plots that plot (i) hours of electricity availability, (ii) days of the month with low voltage, and (iii) number of evening hours of electricity, against different measures of WTP.

Figure 4a: Different measures of reliability versus WTP for grid connection
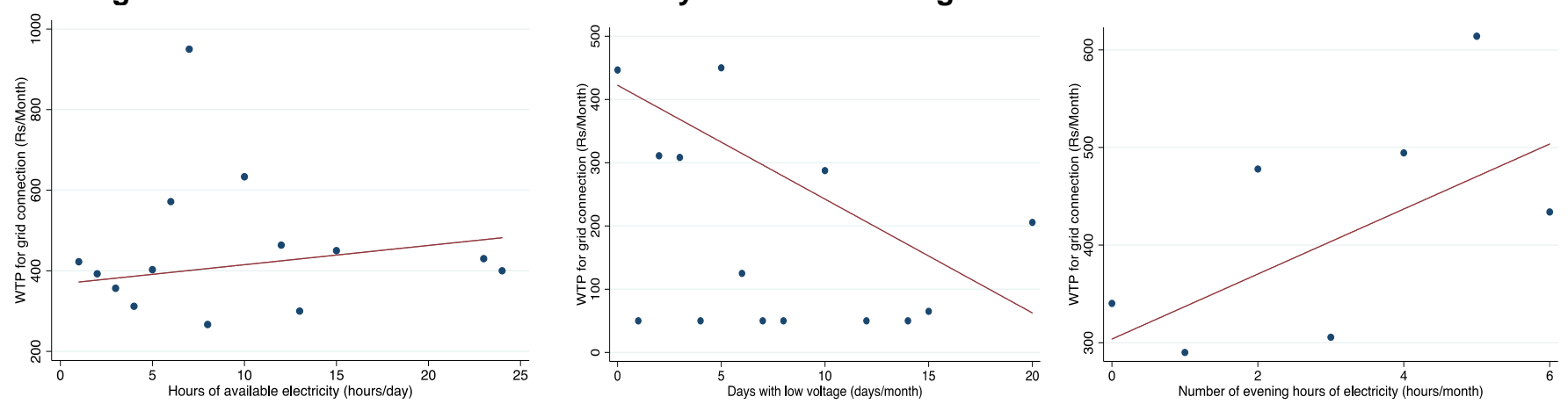

This figure was generated using the ACCESS data (Aklin, 2017).

The first figure here plots hours of available electricity (asked in the survey as how many hours a day is electricity usually available) against the WTP for a grid connection. The second figure plots days with low voltage (asked in the survey as how many days in a month have you experienced voltage that was too low to run appliances) against the WTP for a grid connection. Lastly, the third figure plots the number of evening hours of electricity (asked in the survey as how many hours is electricity usually available between sunset and midnight) against the WTP for a grid connection.

Figure 4b: Different measures of reliability versus WTP for standard package
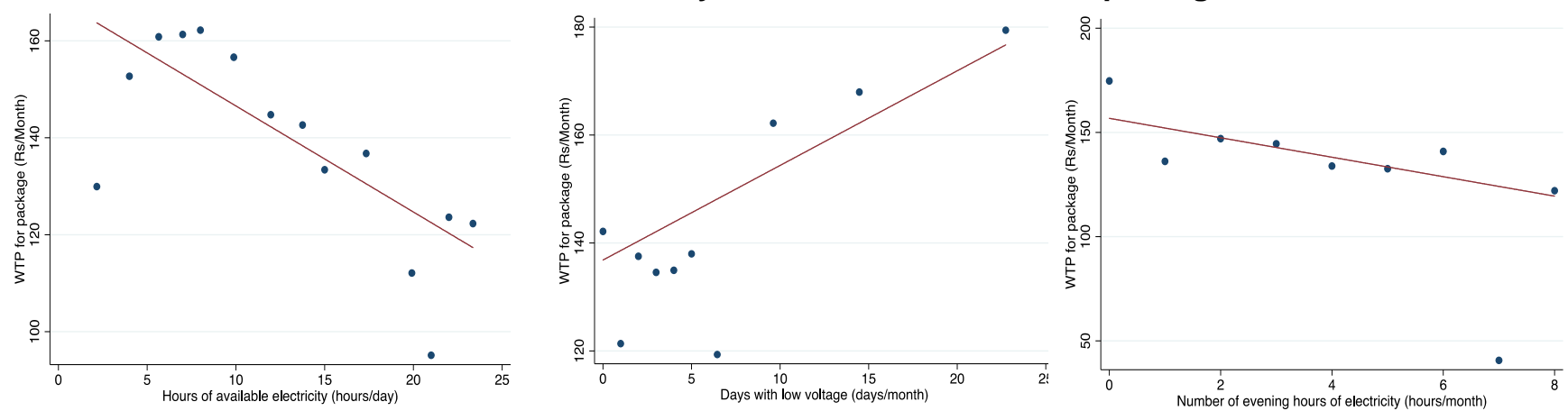

This figure was generated using the ACCESS data (Aklin, 2017).

The first figure here plots hours of available electricity (asked in the survey as how many hours a day is electricity usually available) against the WTP for a standard package - which is asked in the survey as 'how many rupees per month would you be willing to spend for electricity that is available as per your need and would allow you to get artificial light for 12 hours a day, use a fan for 8 hours a day, and charge your mobile phone?' The second figure plots days with low voltage (asked in the survey as how many days in a month have you experienced voltage that was too low to run appliances) against the WTP for the same standard package. Lastly, the third figure plots the number of evening hours of electricity (asked in the survey as how many hours is electricity usually available between sunset and midnight) against the WTP for the same standard package.

The results above similarly reveal some surprising patterns, though none have any causal implications. In Figure 4a, the upward sloping trend in the first and third figures of the panel support a hypothesis 

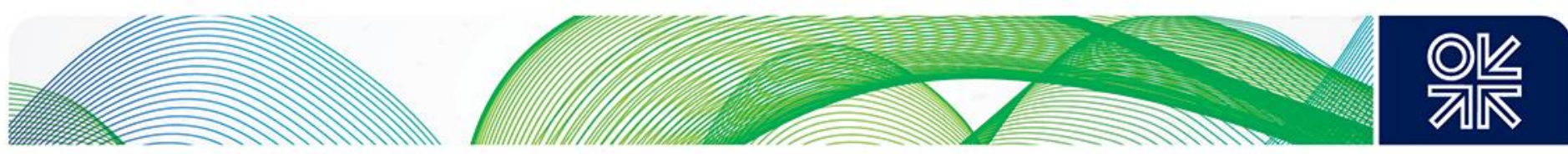

that greater reliability increases WTP, perhaps through a mechanism of increased trust, while the second supports a consistent hypothesis of a negative relationship between low reliability and WTP. In contrast, the panel in Figure $4 \mathrm{~b}$ follows precisely the opposite pattern, which may imply differences in consumer perception of, and WTP for, electricity from the grid $^{14}$ (4a) versus a so-called standard package of lighting, fan, and mobile charging (4b). Further experimental analysis on variations in WTP - based on the ways in which WTP is measured and asked about within a survey - may reveal useful underlying behavioural insights on consumer valuation and decision making.

\section{WTP in technoeconomic planning and optimization models}

At this point, there are a few key takeaways from the existing literature and the small case study on India that are worth summarizing:

1. First, from a socioeconomic and demographic angle, factors such as higher income, educational status, number of children of school-going age, and aspirations for home businesses are consistently associated with an increase in WTP for electricity. In contrast, age, occupation, and household structures have more ambiguous relationships with WTP in the existing literature.

2. From a technical angle, there is variability in WTP for reliable electricity based on the ways in which reliability is measured or presented to consumers: for example, households' WTP differs on the basis of frequency versus duration of outages, and whether the expectation of an outage is communicated beforehand. These measures are complicated further when considering all scenarios of low reliability in low-income countries (such as off-grid, under grid, idle grid) and differences in households' financial means of coping through back-up generation or simultaneous grid and off-grid connections.

3. Lastly, from a behavioural angle, factors such as trust, information, and inattention biases can impact consumers' WTP both positively and negatively. The direction of this effect can often depend on the previously discussed demographic, socioeconomic, and technical parameters. For example, diverse measures of reliability, as well as the way in which information is communicated to consumers, can have significant effects on WTP, via mechanisms like trust. Better understanding of these mechanisms will allow distribution companies and government agencies to develop targeted strategies for building trust with consumers, through a variety of tools such as nudge behavioural design tactics, groundlevel capacity building in cooperation with existing local organizations, and ICT-based communication mechanisms such as SMS updates and e-monitoring platforms.

All in all, there is a need for a growing research agenda and experimental work on these topics that aims to better separate causal effects. In this section, I first consider ways in which the existing structures of technoeconomic planning and decision-support tools can be further enhanced to incorporate insights on the state of knowledge about WTP and consumer behaviour. Thereafter, I lay out a series of proposals for the ways in which these models can be used to advance this research agenda on determinants of WTP.

\footnotetext{
${ }^{14}$ For example, while the utilitarian attribute of reliable electricity with a standard package of lighting, a fan, and mobile charging through a microgrid or isolated solar system connection may be much higher than that of unreliable grid access, the perceived hedonic attributes of grid electricity can be weighted more highly because of factors such as social status associated with the grid versus off-grid services (Borofsky, 2015).
} 

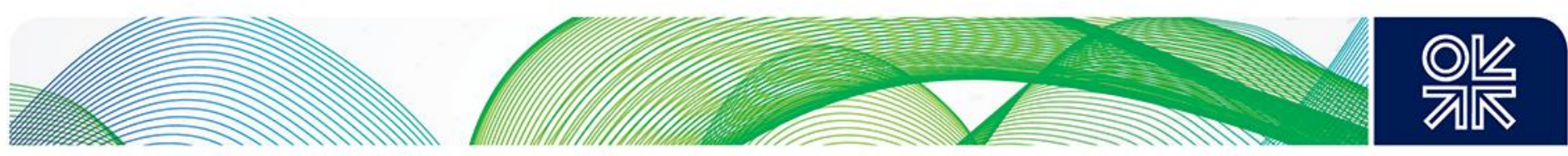

\subsection{Enhancing existing proxy measures in technoeconomic models}

'I cannot help but wonder how many medical catastrophes have occurred in public hospitals because of "no light", how much agricultural produce has gone to waste, how many students forced to study in stuffy, hot air have failed exams, how many small businesses have foundered'

\section{Chimamanda Ngozi Adichie}

Computer-based decision-support tools such as the Reference Electrification Model (REM), developed by the MIT-Comillas Universal Access Lab, use information about areas with poor electricity access to determine the 'best' electrification mode (grid connected, microgrids, or isolated solar systems) for each household or other load centre. The REM is further used to estimate cost and electricity demand and it also simulates preliminary network designs for both larger-scale grid systems and smaller-scale off-grid systems. As the development of these decision-support models advances, there are increasing opportunities for enhancing the proxy measurements that are already used within models like REM. In particular, I will focus on an indirect measure of welfare within this and other models called the Cost of Non-served Energy or CNSE. The CNSE, also sometimes referred to as Value Of Lost Load or VOLL, generally represents the loss of utility (cost) incurred by consumers when there is no electricity at the time of intended use (Borofsky, 2015). Within the REM, this measure is designated by two separate values: one for essential or critical loads and the other for non-essential or non-critical loads. There are numerous ways in which to estimate these values, including the costs of alternatives or substitutes such as kerosene, which may serve as a coping mechanism in times of power loss. Ultimately, however, these substitutive measures tend to be inadequate in their ability to capture the subjective variability that is inherent in this metric for welfare loss. Palit and Bandyopadhyay (2017) argue, for example, that the average tariff for kerosene is a problematic measure, as it is the per unit cost equivalent for a lack of electricity, and is thus unlikely to reflect consumer WTP for actual access. ${ }^{15}$ Nonetheless, when combined with different measures of reliability, as well as insights on socioeconomic, demographic, and behavioural factors, the CNSE can serve as a useful tool for assessing trade-offs in consumer decisionmaking.

One initial step in improving this measure includes separating it into two components as follows:

A. In situations in which electricity access through a particular mode already exists, CNSE-1 represents the loss of welfare to existing customers when supply is unreliable. This can vary based on electrification mode.

B. In situations in which access does not already exist and the government is planning budget allocations between sectors - such as water, education, health, energy - CNSE-2 represents the loss of welfare to potential customers who continue to lack access to electricity services across delivery modes (Rahnama and Perez-Arriaga, 2018).

CNSE-2 can depend on CNSE-1 and has varied utility values based on the type of electricity customer, different time periods, and delivery modes. The existing literature on determinants of WTP - which is closely (inversely) related to the CNSE - can strengthen our understanding and measurements of CNSE-1 and CNSE-2. For example, insights from the literature tell us that the loss of welfare (in terms of CNSE-1) to consumers may be higher for longer outages as compared to frequent (shorter) outages, and the welfare loss diminishes if consumers are provided with prior notice, regardless of electrification mode. Similarly, welfare loss from outages or other forms of poor reliability can vary significantly based on the age of household members, and whether the household is detached or in a shared setting. With regards to CNSE-2, existing data on appliance aspirations among unelectrified households and

\footnotetext{
${ }^{15}$ Aklin (2017), moreover, found that consumers were well aware of the negative health effects of kerosene and 66.04 per cent of respondents preferred that the government subsidize grid electricity, as compared to only 12.37 per cent who wanted more kerosene subsidies.
} 

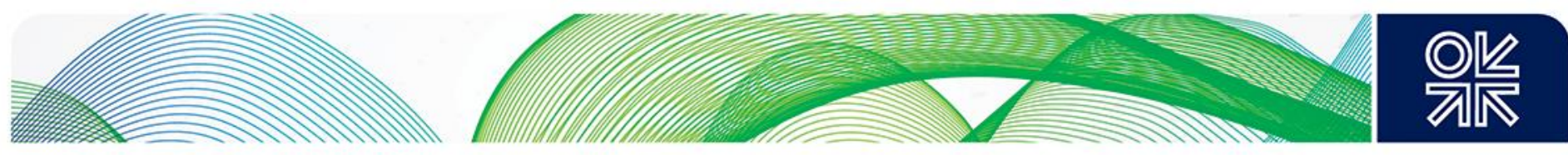

estimated WTP for the use of these appliances, can serve as better proxy measures than the cost of kerosene. For example, as discussed earlier using the ACCESS data, I found that of the 2,610 households that were not currently electrified in the sample (across electrification modes), 100 per cent aspired for lighting appliances, 99 per cent for fans, 18 per cent for irons, 10 per cent for refrigeration, 89 per cent for a television, and 14 per cent for an electric pump, with an average WTP of $120 \mathrm{Rs} / \mathrm{month}$. Existing literature on appliance ownership and aspiration patterns can further serve to clarify what constitutes essential/critical versus non-essential/non-critical loads from a household point of view. For instance, while models may consider the load of a television to be 'non-essential', it is consistently the most highly aspired for appliance across electrification modes in India, potentially due to its being a status symbol, with consequent underlying social signalling mechanisms.

Models such as the REM can draw from the current state of knowledge on WTP in the context of low electricity reliability and the ability to experiment with different 'penalty' values for welfare loss in the CNSE-1 and CNSE-2 scenarios. This expanded and more nuanced measure of CNSE can be used to effectively assess and communicate trade-offs and options to consumers, so that they can make more informed decisions (such as in the experiments proposed in the following section). Not only is an improved understanding of the trade-offs associated with decisions around electricity reliability, financial constraints, appliance ownership and aspirations, and differential lifestyles important for the ways in which it can improve predictions about consumer behaviour, but it also better informs welfare-enhancing policies for grid and off-grid systems (Graber et al., 2018).

\subsection{Novel proposals using technoeconomic models}

Models such as the REM can enable interesting choice experiments that relate closely to the focus of this paper on WTP and reliability. Since the model has the ability to simulate different reliability levels and associated costs for each electrification mode, this information can be used to present hypothetical cost-reliability scenarios to consumers in the field, in order to measure WTP. A subset of the main methods used to measure WTP are presented in Table 7, and a set of experimental proposals is subsequently presented.

Table 7: Choice experiment methods

\begin{tabular}{c|l}
\hline Method & \multicolumn{1}{c}{ Description } \\
\hline $\begin{array}{c}\text { Single-Bounded } \\
\text { Dichotomous Choice }\end{array}$ & $\begin{array}{l}\text { This is among the most common methods used by researchers and involves asking a } \\
\text { respondent if he/she will pay a specified monetary amount to obtain a good and there are } \\
\text { only two choices: yes, or no. This monetary amount, often called a bid value, is varied } \\
\text { across respondents and the discrete choice format mimics a bargaining process. }\end{array}$ \\
\hline $\begin{array}{c}\text { Multi-Bounded } \\
\text { Polychotomous Choice }\end{array}$ & $\begin{array}{l}\text { In this method, respondents are presented with a panel of values and response categories } \\
\text { that have been arranged into a matrix, and are then are asked to mark the degree of } \\
\text { confidence that they feel about paying or not paying for each amount that is listed in the } \\
\text { matrix. }\end{array}$ \\
\hline \multirow{3}{*}{ Payment Cards } & $\begin{array}{l}\text { In this method, the respondent is presented with a list of possible values on a card and } \\
\text { then asked to pick the value that best represents his/her WTP, as well as a second choice. } \\
\text { Oftentimes, the mean of the lower bound (first choice) and upper bound (second choice) is } \\
\text { taken. }\end{array}$ \\
\hline \multirow{2}{*}{ Chontingent Behaviour Experiments } & $\begin{array}{l}\text { Next, in this method, the respondent is asked to choose between pairs of programmes (A } \\
\text { and B), each of which contains different attributes and costs, or to choose to 'do nothing' } \\
\text { (in other words, the status quo), which allows the researcher to obtain information about } \\
\text { the marginal valuation of each attribute. }\end{array}$ \\
\hline $\begin{array}{l}\text { Lastly, this method asks a respondent what he/she would do under specified hypothetical } \\
\text { circumstances. For example, in Jayne et al. (1996), researchers asked respondents in } \\
\text { Kenya, Zimbabwe, and Mozambique what their expected purchase of refined cornmeal, } \\
\text { coarse cornmeal, or other substitutes would be under a variety of price and regulation } \\
\text { scenarios; this stated preference data was combined with revealed preference data (from } \\
\text { the actual purchase of these commodities) to estimate demand functions. }\end{array}$
\end{tabular}

Source: FAO [2000]; Jayne et al [1996] 

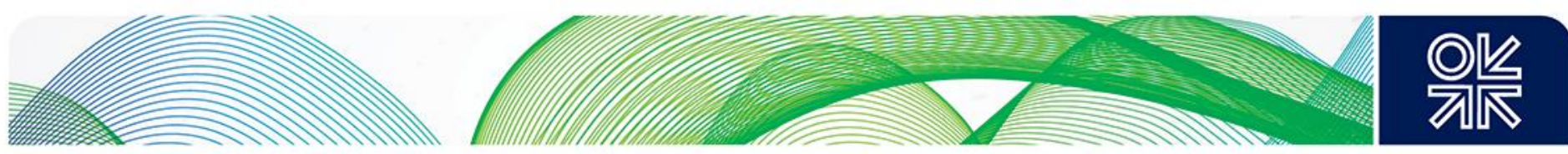

As previously discussed, each of the methods in Table 7 has advantages and disadvantages that can impact how seriously the calculated WTP values for access or reliability can be interpreted. Given the positives and negatives that exist for each of these methods, I try to give a balanced sample of proposals that use a model such as the REM in complementarity with nearly every choice experiment method as follows:

A. A multi-bounded polychotomous choice experiment can be applied using the REM to present consumers with explicit sets of choices, such as 5 hours of reliable electricity in the evening at $\mathrm{XRs}$ /month using the grid, 10 hours of reliable electricity in the afternoon and evening at Y Rs/month using a grid connection with a solar home system, and numerous other combinations of scenarios, depending on the figures that REM can simulate. Given these different sets of choices and subsequent specification of consumers' preferences, a curve that estimates WTP for different reliability levels can be generated.

B. A probabilistic payment card method can be combined with the REM to present consumers with information on a set of hypothetical price increases that are associated with different forms of reliability and cost trade-offs, such as high-impact and low-frequency outages (for example, a 24-hour outage) for grid electricity. Consumers can respond along a scale of 1-5, for example, to represent the level of certainty with which they would pay for a specified price increase in order to avoid the outage scenarios.

C. Using the choice experiment method - in which the respondent is asked to choose between pairs of programmes, each with different attributes and costs - in combination with the REM, a field experiment can be implemented that presents households with pre-set packages of service options, for a combination of grid and off-grid connections, as well as potential pathways and options for moving upward along the package of options toward higher reliability, as ability to pay increases. Choice experiments can be set up using the REM to formalize these subproducts depending on the reliability and quality standards desired, as well as pricing considerations.

D. An ultimate potential research experiment that can be enhanced through the use of the REM involves applying the contingent behaviour method. Within this method, the REM can be used to simulate and present information to the respondent about different costs and reliability options at different times of the day, including scenarios in which outages are communicated and not communicated in advance. The researcher can then ask what the respondent would do in the hours in which electricity is unavailable to them, depending on the different costreliability scenarios that are randomized to the experiment participants.

These ideas serve the purpose of suggesting several research experiments that future researchers working in this area can expand upon in order to grow the literature on the relationship between WTP, reliability, and consumer behaviour in both grid and off-grid settings.

\section{Policy implications and conclusion}

\footnotetext{
'...Too often, planners confront this electricity access gap by increasing supply without attention to how consumers actually use and pay for electricity. A lasting solution is far more complicated than that'.
}

Odarno, 2017

Traditionally, electricity consumers have been subdivided into binary categorizations based on the form of electricity access (such as grid or off-grid). While off-grid systems are well understood to constitute microgrids, minigrids, and standalone solar systems, the gradient of the consumer base that exists between the grid and off the grid is more nuanced. These subtler segmentations of electricity consumers are important, because each faces different degrees of challenges that hold implications for their WTP and demand for the level of service within that category. In some cases, some consumers fall under 

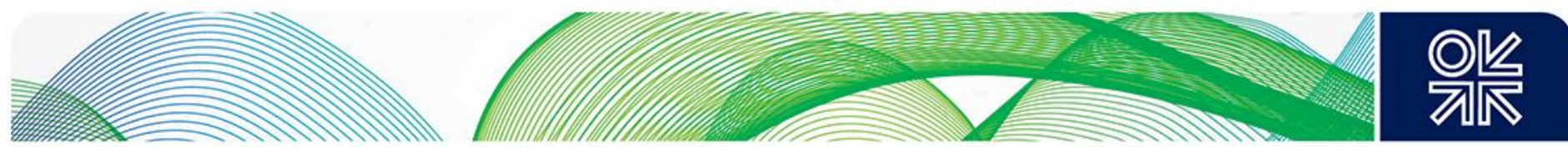

multiple categories simultaneously - using off-grid connections or turning to kerosene to cope with under grid, idle grid, or bad grid connections. The fragmentation of consumers into these different buckets of categories implies that there is no one-size-fits-all approach to measuring and comprehending consumers' preferences, WTP, and valuation of electricity services.

The time is ripe for technoeconomic planning models and energy poverty measurement frameworks to experiment with expanded definitions that move beyond binary metrics. While core measurement frameworks have moved in a multidimensional and multitier direction, as discussed earlier in this paper, there is now opportunity to expand these tiers into more subdivisions that incorporate existing insights on determinants of WTP. For example, within the World Bank MTF, which includes multiple tiers for dimensions such as availability, reliability, and quality, there is potential to integrate and experiment with sub-tiered estimations of WTP based on the existing state of knowledge about the relationship between reliability (duration versus frequency), appliance ownership and aspiration, and WTP across single or multiple connection types. While it is largely infeasible to obtain any form of cross-country universality in these sub-tiers of WTP, such an expansion of the framework nonetheless provides interested parties with a foundation upon which to build and collect additional country-specific information.

Adaptations of energy poverty frameworks and planning models that add socioeconomic, demographic, technical, and behavioural nuance to existing measures for WTP, welfare gain/loss, and CNSE (such as the experiments suggested in Section 4.2) will move the field in a direction that better represents the ground-level realities of low-access and low-reliability consumers. Given the powerful effects that measurement frameworks and optimization tools have on policy, regulation, and large- and small-scale electrification planning across electrification modes, it is imperative to accelerate a research agenda that better quantifies the dynamic preferences, behaviour, and decision making of the energy poor. Future work within this agenda could include panel studies examining the evolution of WTP and household behaviour over time, as consumers gain greater exposure to increasingly reliable electricity from different supply sources. Moreover, further research should underscore the importance of affordability and the dynamic interactions between ability to pay and WTP, including the ways in which consumers' accumulation of capital to invest in appliances can influence their WTP for high-quality electricity services. 

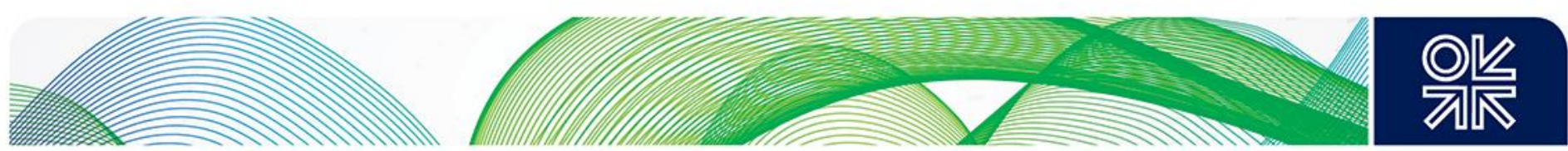

\section{References}

Abdullah, Sabah and P Wilner Jeanty (2009). 'Demand for electricity connection in rural areas: the case of Kenya', Working Paper, University of Bath.

Abdullah, Sabah and Petr Mariel (2010). 'Choice experiment study on the willingness to pay to improve electricity services', Energy Policy, 38(8):4570-4581.

Aklin, Michaël (2017). 'Access to clean cooking energy and electricity: Survey of states in India (ACCESS)', Harvard Dataversse, http://dx.doi.org/10.7910/DVN/ONV9LF.

Aklin, Michaël, Patrick Bayer, SP Harish, and Johannes Urpelainen (2014). 'Information and energy

Bhatia, M. and N. Angelou (2015). 'Beyond Connections: Energy Access Redefined', Executive Summary. IBRD/WB, Washington, D.C.

Blankenship, Brian, Jason Chun Yu Wong, and Johannes Urpelainen (2019). 'Explaining willingness to pay for pricing reforms that improve electricity service in India', Energy Policy 128: 459-69.

Borofsky, Yael (2015). 'Towards a transdisciplinary approach to rural electrification planning for universal access in India', Master's thesis, Massachusetts Institute of Technology.

Bringeus, Amalia and Tove Forsbacka Karlsson (2016). Fossil-fuel subsidy reform and the link between popular opposition and information, Stockholm School of Economics.

Broto, Vanesa Castán, L. Stevens, E. Ackom, J. Tomei, P. Parikh, I. Bisaga, L. Seng To, J. Kirshner, and Y. Mulugetta (2017). 'A research agenda for a people-centered approach to energy access in the urbanizing global south', Nature Energy, 2(10):776.

Bouzarovski, Stefan and Saska Petrova (2015). 'A global perspective on domestic energy deprivation: Overcoming the energy poverty-fuel poverty binary', Energy Research \& Social Science 10: 31-40.

Coville, Aidan and Arndt Reichert (2017). 'Senegal Solar Lights Quality Assurance and Guarantee Impact Evaluation', AEA RCT Registry, December.

Culver, L. (2017). 'Energy poverty: What you measure matters', in Proceedings of the Reducing Energy Poverty with Natural Gas: Changing Political, Business and Technology Paradigms Symposium, Stanford, CA, USA, pp. 9-10.

Elnakat, Afamia, Juan D Gomez, and Nathlie Booth (2016). 'A zip code study of socioeconomic, demographic, and household gendered influence on the residential energy sector', Energy Reports, 2:21-27.

FAO (2000). 'Applications of the contingent valuation method in developing countries', FAO Economic and Social Development Paper 146.

Fisher-Vanden, Karen, Erin T Mansur, and Qiong Juliana Wang (2015). 'Electricity shortages and firm productivity: evidence from China's industrial firms', Journal of Development Economics, 114:172-188.

Garg, Vibhuti, Lourdes Sanchez, Richard Bridle, and Kieran Clarke (2016). 'How to pay the bills? a survey of public attitudes to electricity tariff reform in Rajasthan', International Institute for Sustainable Development, November.

Gertler, Paul J., Kenneth Lee, and A Mushfiq Mobarak (2017). 'Electricity reliability and economic development in cities: A microeconomic perspective', UC Berkeley: Center for Effective Global Action.

Gibson, David (2017). 'Taming a Wicked Problem: Energy Access Planning from an Energy-Poor Perspective, Master's thesis, Harvard University.

Goett, Andrew A., Kathleen Hudson, and Kenneth E Train (2000). 'Customers' choice among retail energy suppliers: The willingness-to-pay for service attributes', The Energy Journal, pages 1-28. 

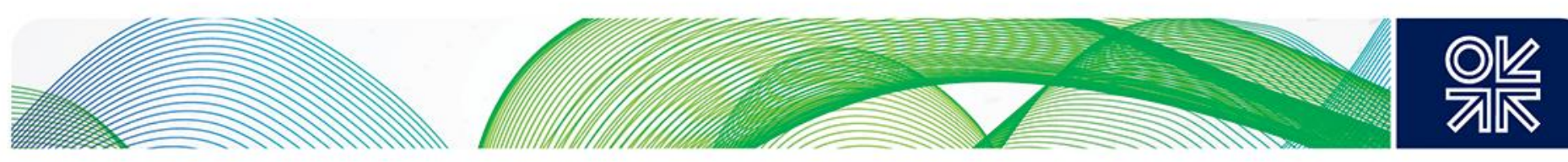

Golden, Miriam and Brian Min (2012). 'Theft and loss of electricity in an Indian state', Journal of the International Growth Centre.

Graber, Sachiko, Tara Narayanan, Jose Alfaro, and Debajit Palit (2018). 'Solar microgrids in rural India: Consumers' willingness to pay for attributes of electricity', Energy for Sustainable Development, 42:3243.

SCC India staff (2017). 'An app that predicts power outage (Urja Mitra comes to the rescue)', Smart Cities Council India.

Groh, Sebastian, Shonali Pachauri, and Narasimha D. Rao (2016). 'What are we measuring? An empirical analysis of household electricity access metrics in rural Bangladesh', Energy for sustainable development 30: 21-31.

Gunatilake, Herath (2012). 'Willingness to pay for good quality, uninterrupted power supply in Madhya Pradesh, India', Asian Development Bank.

Hadker, Nandini, Sudhir Sharma, Ashish David, and T.R. Muraleedharan (1997). 'Willingness to pay for Borivli National Park: evidence from a contingent valuation', Ecological Economics 21:105-122.

Harish, Santosh M., Granger M. Morgan, and Eswaran Subrahmanian (2014). 'When does unreliable grid supply become unacceptable policy? Costs of power supply and outages in rural India', Energy Policy, 68:158-69.

Hensher, David A., Nina Shore, and Kenneth Train (2014). 'Willingness to pay for residential electricity supply quality and reliability', Applied Energy, 115:280-92.

Jayne, Thomas S., Lawrence Rubey, Frank Lupi, David Tschirley, and Michael T. Weber (1996). 'Estimating consumer response to food market reform using stated preference data: evidence from Eastern and Southern Africa', American Journal of Agricultural Economics, 78:820-824.

Khandker, Shahidur R., Hussain A. Samad, Rubaba Ali, and Douglas F. Barnes (2012). 'Who benefits most from rural electrification? Evidence in India', Policy Research Working Paper 6095.

Kueck, John D (2005). 'Measurement practices for reliability and power quality', Technical report, ORNL.

Lal, Sumir (2005). 'Can good economics ever be good politics? Case study of the power sector in India', Economic and Political Weekly, pages 649-56.

Lee, Kenneth, Edward Miguel, and Catherine Wolfram (2017). 'Electrification and economic development: A microeconomic perspective', UC Berkeley: Center for Effective Global Action.

Lee, Kenneth, Edward Miguel, and Catherine Wolfram (2016b). 'Experimental evidence on the demand for and costs of rural electrification', Technical report, National Bureau of Economic Research.

Lins, Clarissa (2014). 'Providing Electricity to Rio de Janeiro's favelas', The Guardian, 18 March.

McRae, Shaun (2015). 'Infrastructure quality and the subsidy trap', American Economic Review 105, no. 1: 35-66.

M-KOPA Labs (2017). 'Lessons Learnt', Note, November.

Mirza, Bilal and Adam Szirmai (2010). 'Towards a new measurement of energy poverty: A crosscommunity analysis of rural Pakistan' UNU-MERTI Working Papers, No. 024.

Nussbaumer, Patrick, Morgan Bazilian, and Vijay Modi (2012). 'Measuring energy poverty: Focusing on what matters', Renewable and Sustainable Energy Reviews 16, no. 1: 231-43.

Odarno, Lily (2017). '1.2 Billion People Lack Electricity - Increasing Supply Alone Won't Fix the Problem', World Resources Institute. 

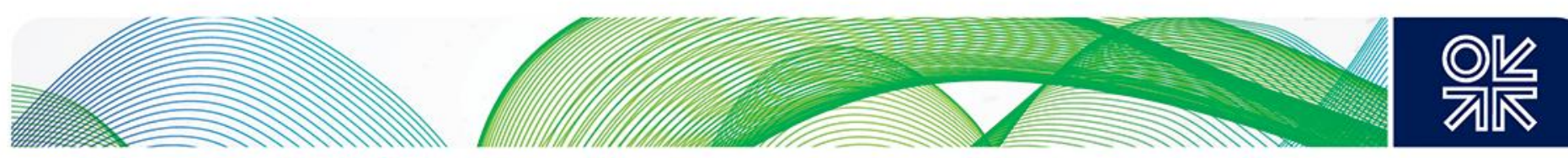

Oseni, Musiliu O. et al. (2017). 'Self-generation and households' willingness to pay for reliable electricity service in Nigeria', The Energy Journal, 38(4).

Palit, Debajit and Kaushik Ranjan Bandyopadhyay (2017). 'Rural electricity access in India in retrospect: A critical rumination', Energy Policy, 109:109-20.

Pelz, Setu, Shonali Pachuari, and Sebastian Groh (2018). 'A critical review of modern approaches for multidimensional energy poverty measurement', Wiley Interdisciplinary Reviews: Energy and Environment 7(6): e304.

Prayas (Energy Group). Electricity Supply Monitoring Initiative - Summary Analysis, January 2018. ESMI, 2018.

Rahnama, Roxanne (2018). 'Essays on the attitudes, behavior, and decision-making of incomeconstrained electricity consumers: implications for integrative grid and off-grid business model planning', Master's thesis, Massachusetts Institute of Technology.

Rahnama, Roxanne and Ignacio Perez-Arriaga (2018). 'Electrification planning with a focus on human factors', Oxford Energy Forum (115): 30-34.

Reinders, Kunaifi and Angèle Reinders (2018). 'Perceived and Reported Reliability of the Electricity Supply at Three Urban Locations in Indonesia', Energies 11(140), January.

Rockenbach, Bettina, Sebastian Tonke, and Arne Weiß (2015). 'Improving Payment Behavior for Water in Rural Namibia', AEA RCT Registry.

Shrivastava, Bhuma (2017). 'The Army of Women Battling India's \$10 Billion Power Problem', Bloomberg,

Sinha, Praveer (2017). Meeting at Tata Power DDL, New Delhi, July.

Sovacool, Benjamin K. (2014). 'What are we doing here? Analyzing fifteen years of energy scholarship and proposing a social science research agenda', Energy Research \& Social Science, 1:1-29.

Steinbuks, Jevgenijs and Vivien Foster (2010). 'When do firms generate? evidence on in-house electricity supply in Africa', Energy Economics, 32(3):505-14,.

Sudarshan, Anant (2017). 'Nudges in the marketplace: The response of household electricity consumption to information and monetary incentives', Journal of Economic Behavior \& Organization, Vol. 134: 320-35.

Taale, Francis and Christian Kyeremeh (2016). 'Households' willingness to pay for reliable electricity services in Ghana', Renewable and Sustainable Energy Reviews, 62:280-8.

Tait, Louise (2017). 'Towards a multidimensional framework for measuring household energy access: Application to South Africa', Energy for Sustainable Development, 38: 1-9, June.

Thaler, Richard and Cass Sunstein (2008). Nudge: Improving Decisions About Health, Wealth, and Happiness, Yale University Press.

Townsend, Alan (2000). 'Energy access, energy demand and the information deficit', Energy Services for the World's Poor, Energy and Development Report, Energy Sector Management Assistance Programme, The World Bank.

World Bank (2015). 'Bringing Electricity to Kenya's Slums: Hard Lessons Lead to Great Gains'. 